\title{
Providing Quantitative Information and a Nudge to Undergo Stool Testing in a Colorectal Cancer Screening Decision Aid: A Randomized Clinical Trial
}

Peter H. Schwartz, MD, PhD, ${ }^{1,2,3,4}$ Susan M. Perkins, PhD, ${ }^{4,5}$ Karen K. Schmidt, RN, MSN, ${ }^{1}$ Paul F. Muriello, BA, ${ }^{1,2}$ Sandra Althouse, MS, ${ }^{5}$ and Susan M. Rawl, PhD, RN, FAAN ${ }^{4,6}$

1. Department of Medicine, Indiana University School of Medicine

2. Indiana University Center for Bioethics

3. Philosophy Department, Indiana University School of Liberal Arts, Indianapolis

4. Indiana University Simon Cancer Center

5. Department of Biostatistics, Indiana University School of Medicine

6. Indiana University School of Nursing

\section{Corresponding Author:}

Peter H. Schwartz, MD, PhD

Indiana University Center for Bioethics

410 W. $10^{\text {th }}$ St., Ste. 3100

Indianapolis, IN 46202

Telephone: 317-278-4034

Fax: 317-278-4050

Email:phschwar@iu.edu

Department and institution where the work was done:

Indiana University Center for Bioethics, and

Department of Medicine, Indiana University School of Medicine,

This is the author's manuscript of the article published in final edited form as:

Peter H. Schwartz, Susan M. Perkins, Karen K. Schmidt, Paul F. Muriello, Sandra Althouse, \& Susan M. Rawl.

(2017). Providing Quantitative Information and a Nudge to Undergo Stool Testing in a Colorectal Cancer Screening Decision Aid: A Randomized Clinical Trial. Medical Decision Making, 37(6), 688-702. 
Meetings at which the work was presented:

- Oral presentation at $35^{\text {th }}$ Annual Meeting of the Society for Medical Decision Making, Baltimore, MD, Oct. 22, 2013. Abstract published: Schwartz PH, Muriello PF, Perkins SM, Schmidt KK, Rawl SM, “Adding natural frequency data to a decision aid for colorectal cancer screening: Results of a randomized trial,” Med Decis Making Feb. 2014; 34: E29-30.

- Oral presentation at $36^{\text {th }}$ Annual Meeting of the Society for Medical Decision Making, Miami, FL, October 21, 2014: Abstract published: Schwartz PH, Perkins SM, Schmidt KK, Muriello PF, Althouse S, Rawl SM "Presenting Stool Testing as the Default Option for Colorectal Cancer Screening: Results of a Randomized Trial,” Medical Decision Making Jan. 2015; 35: E39.

Grant support: Financial support for this study was provided by grants from the American Cancer Society and from Indiana University Health (previously Clarian Health), as listed below. The funding agreement ensured the authors' independence in designing the study, interpreting the data, writing, and publishing the report:

- American Cancer Society: Cancer Control Career Development Award for Primary Care Physicians (CCCDA-10-085-01), 07/01/10 - 06/30/14. PI: Peter Schwartz.

- Indiana University Health Values Grant: Giving Patients Quantitative Information about the Risks of Colorectal Cancer and the Benefits of Screening: A Randomized Trial of a Computer-based Presentation (VFR-320), 08/01/10 - 07/31/12. PI: Peter Schwartz.

\section{Manuscript text word count: 4309}

Running head: Quantitative Information and a Nudge in a DA

Trial Registration: ClinicalTrials.gov ID\# NCT01415479 


\begin{abstract}
:
Background: Guidelines recommend that patient decision aids provide quantitative information about probabilities of potential outcomes, but the impact of this information is unknown. Behavioral economics suggests that patients confused by quantitative information could benefit from a "nudge" towards one option. We conducted a pilot randomized trial to estimate the effect sizes of presenting quantitative information and a nudge.
\end{abstract}

Methods: 213 primary care patients eligible for colorectal cancer screening viewed basic screening information and were randomized to view (a) quantitative information (quantitative module), (b) a nudge towards stool testing with the fecal immunochemical test (FIT) (nudge module), (c) neither a nor b, or (d) both a and b. Outcome measures were perceived colorectal cancer risk, screening intent, preferred test, and decision conflict, measured before and after viewing the decision aid, and screening behavior at 6 months.

Results: Patients viewing the quantitative module were more likely to be screened than those who did not $(\mathrm{p}=0.012)$. Patients viewing the nudge module had a greater increase in perceived colorectal cancer risk than those who did not $(\mathrm{p}=.041)$. Those viewing the quantitative module had a smaller increase in perceived risk than those who did not ( $\mathrm{p}=.046)$, and the effect was moderated by numeracy. Among patients with high numeracy who did not view the nudge module, those who viewed the quantitative module had a greater increase in intent to undergo FIT ( $p=.028)$ than did those who did not.

Limitations: Limited sample size and single healthcare system.

Conclusions: Adding quantitative information to a decision aid increased uptake of colorectal cancer screening, while adding a nudge to undergo FIT did not increase uptake. Further research on quantitative information in decision aids is warranted. 


\section{Introduction:}

Quantitative Information and Colorectal Cancer Screening:

Decision aids aim to improve patient decision-making in preference-sensitive situations, i.e. where there is no single medically favored option. ${ }^{1-5}$ A critical question is how or what information decision aids should provide. Many experts recommend that decision aids disclose probabilities of possible outcomes to support fully informed decisions. ${ }^{4,6-10}$ For decision aids regarding screening tests, guidelines such as the International Patient Decision Aids Standards (IPDAS) recommend that decision aids disclose absolute risk, risk reduction and the chance of negative outcomes. ${ }^{4,7}$

It is unclear, however, whether quantitative information improves patient decisions. Describing risk with numbers or figures rather than verbally reduces patient concern and may increase willingness to accept treatment. ${ }^{11-14}$ But it is not clear whether these differences reflect improved decision-making. Many individuals have difficulty interpreting and applying quantitative information: more than half of US adults do not understand simple mathematical concepts of percentage and frequency. ${ }^{15,16}$ Even when quantitative information is understood, heuristics and biases interfere with rational processing. ${ }^{17-19}$ According to some theories, when people learn numbers, they also store a separate "gist impression" that involves emotional factors and significantly affects behavior. ${ }^{18,20}$

Previous studies have not directly measured the impact of including quantitative information in decision aids. A recent Cochrane review of randomized, controlled trials of $\mathrm{DAs}^{21}$ identified 25 studies involving decision aids that presented probabilities. Patients who viewed decision aids with probabilities were more likely to correctly answer probability questions than controls, but presenting probabilities did not affect other outcomes. Further, only 1 of the 25 studies compared decision aids that were identical except for inclusion of probabilities, and this single trial used scripts read to elderly participants. ${ }^{22}$ Some experts have questioned whether all patients should be given detailed quantitative information and have called for additional research. ${ }^{23-27}$

Colorectal cancer screening provides an excellent context to investigate the impact of presenting quantitative information. While national guidelines recommend that all individuals aged 50-75 years undergo colorectal cancer screening, the choice of a screening test is 
preference-sensitive, since multiple tests are approved. ${ }^{28-30}$ The two most common tests are colonoscopy every 10 years and annual stool testing, ${ }^{31}$ and each has important advantages and disadvantages. While colonoscopy provides the most complete examination of the colon, patients must undergo an uncomfortable prep and face risks including bleeding and colon perforation. Stool testing, such as the fecal immunochemical test (FIT), is non-invasive and performed at home. FIT has lower sensitivity than colonoscopy, must be repeated annually, and positive tests must be followed up with colonoscopy; ${ }^{28-30}$ however, when performed annually FIT may provide long-term risk reduction that rivals colonoscopy. ${ }^{32,33}$ Of the 7 colorectal cancer screening decision aids that have been tested in randomized controlled trials, 4 provided some quantitative information about the baseline risk of colorectal cancer, risk reduction provided by the two tests, or frequency of negative outcomes, ${ }^{22,34-36}$ while 3 did not. ${ }^{37-39}$

\section{$\underline{\text { Social norms }}$}

Providing quantitative information about colorectal cancer screening tests might make patients unsure which to choose, and thus could delay screening. Such a decline would be particularly unfortunate if it stemmed from confusion or misunderstanding. The field of behavioral economics has designed and tested interventions, often called "nudges,"40,41 that utilize nonrational, nonconscious features of human thought to improve decisions. For example, people are less likely to litter or cheat on their taxes if they believe that relatively few people do so ("social norms"). ${ }^{42-44}$ Some have suggested that nudges be used more frequently in medicine..$^{40,45-47}$

A social norms "nudge" towards one of the available colorectal cancer screening tests could help patients who are unsure which test to choose, perhaps due to being confused by quantitative data. FIT is a natural candidate for such nudging, since it is noninvasive and easy to perform. Studies have found that offering FIT results in higher screening uptake than recommending colonoscopy. ${ }^{48,49}$

In this paper, we report a pilot randomized controlled trial to test the impact of providing patients with quantitative information regarding colorectal cancer screening and of presenting a social norms nudge to FIT in a decision aid. We used a 2x2 full-factorial between-subjects design with 6-month follow-up (Figure 1). All patients viewed basic information regarding colorectal cancer screening tests and then were randomized to view (1) no further information 
(Basic-Info-Only group), (2) quantitative information regarding colorectal cancer risk and screening tests (Quantitative group), (3) a nudge to undergo FIT (Nudge group), or (4) both quantitative information and the nudge (Quantitative+Nudge group). We aimed to answer two research questions:

1) In a decision aid regarding colorectal cancer screening, does the addition of (a) quantitative information, (b) a nudge to FIT, or (c) both, impact perceived colorectal cancer risk, intent to be screened, decision conflict, test preference, or uptake of screening at six months, compared to viewing basic information only?

2) Does numeracy moderate any effects?

Since this was the first study to measure the impact of providing quantitative information and a nudge to FIT, compared to basic information alone, our primary goal was to estimate effect sizes for consideration in designing a larger, fully-powered trial.

\section{Methods:}

\section{Study Setting}

The study was conducted from August 2011 through February 2013 at five primary care sites in the Indiana University Health system serving a racially and ethnically diverse population of central Indiana. The study was approved by the Indiana University Institutional Review Board.

Inclusion/ Exclusion Criteria:

Participants were screening-eligible male and female adults, 50 to 75 years old who were scheduled to be seen at participating primary care clinics. Participants were eligible if they had not had colonoscopy in the last 10 years, sigmoidoscopy in the last 5 years, or stool blood test in the past year. We excluded patients who: (1) had a diagnosis or family history conferring elevated risk for colorectal cancer, (2) were undergoing workup for symptoms consistent with colorectal cancer, (3) did not read English, or (4) were instructed by health care provider to avoid colorectal cancer screening.

\section{$\underline{\text { Recruitment process }}$}


Twenty-five primary care physicians at five participating practices were asked for consent to approach their eligible patients, and 24 (96\%) agreed. Patients who appeared to be eligible according to the electronic medical record were sent an introductory letter and contacted by phone to assess eligibility. Eligible patients who agreed to participate met a study team member for approximately one hour in the clinic, often coinciding with a provider appointment.

\section{Study Procedure}

After providing written informed consent, participants completed a self-administered paper baseline survey (T0) in the presence of a research assistant who was available to answer questions. Participants were then randomly assigned to one of four experimental groups.

The biostatistics team generated the randomization scheme with stratification based on practice site, gender, and age (50 to $<65$ years old and 65-75 years old). Group assignments were sealed in sequentially numbered opaque envelopes. The research assistant determined the participant's group assignment by opening the next sequentially numbered envelope from the appropriate strata and then displayed the appropriate decision aid on a laptop computer.

Immediately after viewing the decision aid, participants completed a self-administered paper post-intervention survey (T1). Six months later, participants were contacted by phone to assess screening uptake (T2) and the electronic medical record was reviewed for confirmation of screening for patients who had signed a medical record release form (Figure 2).

\section{Decision Aids:}

Each decision aid consisted of PowerPoint slides with text, figures, and an audio track, viewed on a laptop controlled by the patient. We created three modules and then combined these to create a decision aid for each group, as follows:

- Basic information group: Basic information module only;

- Quantitative group: Basic information module, followed by Quantitative module;

- Nudge group: Basic information module, followed by Nudge module

- Quantitative+Nudge group: Basic information module, followed by Quantitative module, followed by Nudge module.

Each decision aid had identical introductory and concluding slides. 
We designed initial versions of the modules based on the extensive literature regarding evidence-based communication, ${ }^{50-52}$ risk communication, ${ }^{9,10,18,20,53-56}$ behavioral economics, ${ }^{40,45,46,57,58}$ lifetime colorectal cancer incidence and mortality for average risk individuals, ${ }^{32}$ and patient preferences and interest in information about colorectal cancer screening. ${ }^{59-70}$ We reviewed a variety of models for risk reduction provided by colonoscopy and FIT, ${ }^{32,71-73}$ eventually choosing to use estimates provided by the SimCRC model. ${ }^{71,74,75}$

Draft forms of the modules were reviewed by 3 experts in colorectal cancer screening and patient communication to evaluate face validity, message appropriateness, and clarity. In addition, cognitive interviews were conducted with nine patients who were eligible for the study (but not enrolled) who viewed all modules to obtain feedback on their ability to comprehend the messages, graphs, and visuals. Final edits were made to the modules based on expert and patient feedback. See Appendix for sample slides from each module.

The Basic Information module showed a six-minute video produced by the American Cancer Society that provides information about colorectal cancer and screening tests, ${ }^{76}$ followed by four PowerPoint slides summarizing advantages and disadvantages of colonoscopy and FIT. This module presented no quantitative information on risk or risk reduction.

The Quantitative module included six slides with numbers and icon charts presenting the following values for average risk individuals:

(1) lifetime colorectal cancer incidence (6\%, or 60 per 1000) and colorectal cancer mortality (3\%, or 30 per 1000), assuming no screening,

(2) lifetime colorectal cancer mortality given regular screening with colonoscopy $(0.46 \%$, or 4.6 per 1000) or with FIT (0.6\%, or 6 per 1000), according to the SimCRC model, ${ }^{32}$

(3) frequency of an individual FIT turning positive (50 per 1000) and of serious complications from colonoscopy (1-2 per 1000).

The quantitative module concluded with a bar chart displaying average lifetime colorectal cancer mortality with no screening, with colonoscopy, and with annual FIT.

The Nudge module included three slides that showed graphics and simple text, with an audio track delivering the following messages:

(1) "Given the advantages and disadvantages of both tests, many people have a hard time deciding which test to choose.” 
(2) "Many people who do not want a colonoscopy, or are unsure about which test to choose, get a stool test, and it's a perfectly reasonable option.”

(3) “The stool test protects you almost as much as colonoscopy. Either test protects you much more than getting no screening at all.”

(4) "And even if you choose to get the stool test now, you can always get a colonoscopy later.”

(5) “In summary, if you don’t want to have a colonoscopy right now, or don’t know which test to choose, the stool test could be the right one for you.”

These messages were chosen since they could be expected to encourage selection of the stool test, either rationally or based on non-rational mechanisms, often studied in the social influence literature ${ }^{42-44}$ or behavioral economics. ${ }^{40-41}$ Saying that "many people” choose the stool test, in message (2), suggests that a social norm favors this test, as does calling it "perfectly reasonable." Message (3) encourages patients to see the two tests as similarly efficacious. Message (4) aims to make the stool test attractive for those who wish to procrastinate regarding a final decision.

\section{$\underline{\text { Measures }}$}

- Perceived risk of colorectal cancer was assessed at baseline (T0) and immediately postintervention (T1) using a single item: "How likely is it that you will get colon cancer sometime during your life?” with a seven-point response option where 1 = very unlikely and 7 = very likely.

- $\quad$ Intent to be screened for colorectal cancer was measured at T0 and T1 with three separate items: "Do you plan to get a [colon test / colonoscopy / stool test] within the next 6 months?” each with response options of: Definitely, Probably, May or may not, Probably not, and Definitely not. ${ }^{77}$

- $\quad$ Test choice if screened was measured at T0 and T1 using a single item: "If you have a colon test, which one would you choose?” Response options were: Stool test, Colonoscopy, Other, Don't Know.

- Decision conflict was assessed at T0 and T1 using the Decision Conflict Scale, a sixteen-item instrument that assesses patients' subjective feeling regarding the decision process over five areas. Each item is a Likert-style question with five-point response option, where 1= 
strongly agree and $5=$ strongly disagree, summed to create a total Decision Conflict score. ${ }^{78}$ The Cronbach alpha was .94).

- Numeracy was assessed at T1 with the Subjective Numeracy Scale, a validated instrument that involves 8 Likert-type questions regarding the individual's preference for or dislike of numeric information and their perception of their ability to understand it. Each item has a sixpoint response option, with items summed to create a total numeracy score. ${ }^{79,80}$ The Cronbach alpha was 85

- Screening uptake was assessed by checking the patient's EHR for documentation of stool test and colonoscopy completion within 6 months of enrollment. In addition, patients were asked to self-report during the six-month follow-up phone call (T2) whether they had a colonoscopy, stool test, or other colon test since enrollment. For patients who did not give permission to check their EHR, self-report of screening behavior was accepted (5 in Basic Info Only, 5 in Quantitative, 8 in Nudge, and 4 in Quantitative+Nudge). Patient reports of screening uptake were accepted even if a check of the EHR did not reveal report of a completed test, due to the possibility of obtaining these tests elsewhere (3 in Basic Info Only, 3 in Quantitative, 1 in Nudge, and 2 in Quantitative+Nudge).

For two patients (both in the Basic Info Only group), an apparent inconsistency regarding screening uptake was addressed by consensus of the research team. A member of the research team reviewing the electronic health record for these patients found specific information suggesting they were mistaken to believe that they had a FIT test. The principal investigator presented the information to the research team, resulting in consensus to change recorded screening behavior for one patient from FIT and colonoscopy to just colonoscopy, and, for the other patient, from FIT to no screening.

\section{Statistical Methods:}

All analyses were conducted using SAS Version 9.3 (Cary, NC). The significance level was set at 0.05 . Due to the pilot nature of the study and limited number of outcomes, we did not perform multiple comparison adjustments. Sample sizes were determined based on data from a preliminary uncontrolled study that showed an average increase in intent to undergo screening of approximately 0.5 standard deviations after viewing qualitative and quantitative information. We assumed the same increase for the Quantitative group and no change for the Basic Info Only 
group after the intervention for intent to undergo screening in the current study. A sample size of 64 per group was needed to detect this difference with $80 \%$ power using a two-sample t-test and level of significance 0.05. As we intended to use analysis of covariance (ANCOVA) to analyze differences, we expected our power would be higher than $80 \%$ overall.

All models described below included covariates for practice site, gender, and age (50 to < 65 years old and 65-75 years old). For perceived risk, intent to screen, and decision conflict outcomes, the changes in scores from T0 to T1 were compared using ANCOVA models and treatment effects estimated from these models. The T0 score for each of these outcome was treated as a covariate in these models. First, to examine the effects of our two interventions, models were fit that included main effects for quantitative and nudge intervention and their interaction. Next, to see if numeracy moderated the effects of either intervention, models were fit that included quantitative, nudge, numeracy (high vs low in relation to the median) and all higher-order interactions. For each model, interactions were removed if they were not significant. This was done by removing the 3-way interaction first (if applicable), then two-way interactions one at a time by highest p-value. To check for overall changes in scores over time (i.e., assuming no interactions or main effects), an intercept only model was used.

“Test preference” was calculated from Screening Intent and Test choice if screened as follows. If the patient answered Definitely or Probably on the Screening Intent question, the answer on Test choice if screened was coded as the patient's Test preference (Colonoscopy, FIT, or other). Patients who answered May or May Not, Probably Not, or Definitely Not on Screening Intent were coded as having a Test preference of 'Do not intend to be screened'. Patients who answered “Don’t Know” on Screening Intent or Test choice if screened were coded as having Test Preference of Don't Know. Test preference was examined before and after intervention and proportions of patients who changed their preference at all or from something other than FIT at T0 to FIT at T1 was calculated, then compared across groups using chi-square tests and logistic regression models.

Finally, self-reported completion of screening tests at the 6 month phone interview was compared using logistic regression models. As in the change models above, all interactions were initially included and removed if not significant. In addition, we performed a sensitivity analysis for the two cases where screening status was determined by consensus, switching the yes/no 
decision for uptake. There was no impact on the results, so only the consensus results are reported.

\section{Results:}

Study Population:

Overall, 227 patients were randomly assigned to Basic-Information-Only, Quantitative, Nudge, and Quantitative+Nudge groups (Figure 3). Fourteen randomized patients were later excluded from analysis because they were found to be up-to-date with screening at enrollment, resulting in a final sample size of 52 for Basic Information Only, 56 for Quantitative, 53 for Nudge, and 52 for Quantitative+Nudge. Average age was approximately 56 years. The majority of participants were female, and white. There were no significant differences on demographic variables or outcomes at baseline (T0) between the groups (Table 1).

Changes in Perceived Risk, Decision Conflict, and Intent to Screen from baseline (T0) to immediately post-intervention (T1) are depicted in Figure S1. Overall (i.e. ignoring intervention received), there were statistically significant increases (or decreases for Decision Conflict) for all outcomes $(\mathrm{p}<.001)$ from T0 to T1. We examined whether the type of intervention received affected these changes (Research Question 1) and if numeracy moderated these effects (Research Question 2).

\section{Research Question 1:}

Perceived Risk, Intent to Screen, and Decision Conflict outcomes: There were no interactions between the quantitative and nudge interventions for any of the outcomes (Table 2). Patients who viewed the quantitative intervention had a smaller increase in Perceived Colorectal Cancer Risk ( $\mathrm{p}=0.046$ ) than patients who did not. Patients who viewed the nudge intervention had a significantly larger increase in Perceived Colorectal Cancer Risk $(\mathrm{p}=.041)$ than patients who did not. There were no significant effects of the quantitative or nudge intervention on Colorectal Cancer Screening Intent, FIT Intent, or Decision Conflict

Test Preference: Descriptive statistics for screening test preferences before and after the interventions are shown in Table 3. Post hoc tests using conditional logistic regression indicated that, overall, the percent that did not intend to screen was lower at T1 than at T0 $(\mathrm{p}<0.001)$. 
These decreases did not differ by intervention group $(\mathrm{p}=0.39)$. Overall, there were no group differences in the percent changing their preference from T0 to T1 (Table 4, p = .48). From 37\% to $50 \%$ of patients changed their test preference at $\mathrm{T} 1$. When comparing the percent of patients who changed their preference from colonoscopy, don't know, or none (i.e. not FIT) to FIT, changes ranged from $21 \%$ to $43 \%$. Again there were no group differences overall (Table 4, pvalue=0.148).

Uptake: Patients in the quantitative groups were more likely to complete a colorectal cancer screening test ( $p=0.012$; Table 5). There were no other significant effects for the quantitative or nudge interventions.

Post hoc, we used logistic regression to explore the potential effects of Perceived Risk on Uptake to explore whether it might mediate the effect of the intervention on uptake. Perceived Risk at T1 was not associated with uptake.

\section{Research Question 2:}

Perceived Risk, Intent to Screen, and Decision Conflict outcomes: When including numeracy in the models, there were two significant interactions (Table 6). The numeracy, quantitative intervention and nudge intervention three-way interaction was significant for FIT Intent ( $\mathrm{p}=.025)$. Patients with high numeracy who did not view the nudge intervention had greater increases in FIT Intent when viewing the quantitative intervention compared with not viewing it $(\mathrm{p}=.028)$. Among those with high numeracy who did view the nudge intervention and those with low numeracy (whether they viewed the nudge intervention or not), the quantitative intervention had no effect on FIT Intent.

There was a significant two-way interaction between numeracy and the quantitative intervention for Perceived Risk $(\mathrm{p}=.003)$. Among those with high numeracy, the two groups receiving quantitative information had smaller increases in Perceived Colorectal Cancer Risk $(\mathrm{p}<.001)$ than the two groups who did not; whereas the quantitative intervention had no effect on Perceived Colorectal Cancer Risk among those with low numeracy $(\mathrm{p}=.46)$.

Finally, there were two significant main effects of numeracy for Colorectal Cancer Screening Intent $(\mathrm{p}=.008)$ and Decision Conflict $(\mathrm{p}=<.001)$. Those with high numeracy had larger increases in Colorectal Cancer Screening Intent, and larger decreases in Decision Conflict than those with low numeracy. 
Test preference: In logistic regression, those with higher numeracy had greater odds of changing to FIT at $\mathrm{T} 1$ ( $\mathrm{p}=.027, \mathrm{OR}=2.16,95 \%$ CI: 1.09, 4.27). However, there were no intervention group differences in change in test preference or change from not FIT to FIT by numeracy levels using logistic regression or chi-square tests (Table 4).

Uptake: As with the models not accounting for numeracy, only the quantitative effect for colorectal cancer uptake was significant $(p=0.015)$ (Table 5).

\section{Discussion:}

Our study is the first to use a randomized trial design to estimate the effects of adding quantitative information to a decision aid, providing a direct test of one aspect of current recommendations for the design of decision aids. Our study is also the first to measure the impact of presenting a social norms nudge towards stool testing for colorectal cancer screening in a decision aid. We had three notable findings.

First, viewing quantitative information significantly increased uptake of screening at six months. This provides support for recommendations that decision aids disclose such information to patients. No impact on patient behavior has been found in randomized trials comparing more complex vs. simpler decision aid, out of 13 relevant trials included in a recent review. ${ }^{21}$

The way we presented quantitative information may have influenced the observed impact on screening uptake. First, the quantitative module presented information about colorectal cancer risk and risk reduction over a lifetime rather than a shorter period. The magnitude of risk and risk reduction is larger over longer timeframes, and larger numbers have been shown to have greater impact than smaller ones. ${ }^{81,82}$ Second, our quantitative module included a bar chart that can be seen as conveying relative risk information, since the Y-axis height is the baseline mortality rate. Research has shown that relative risk information has a larger impact than absolute risk on perception of benefit. ${ }^{83-85}$

Our second notable finding is that viewing quantitative information significantly reduced perceived colorectal cancer risk, and this effect was moderated by numeracy. This is consistent with previous research. Studies have found that individuals overestimate their probability of getting or dying of cancer, ${ }^{86}$ and that being informed about the probability of dying of a cancer reduces estimates of risk. ${ }^{27,87}$ Previous research has also shown that people with higher 
numeracy skills are more likely to be influenced by quantitative information than those with lower numeracy skills. ${ }^{88-90}$

Third, viewing the social norms nudge significantly increased perceived colorectal cancer risk, although the Nudge module did not include any information about the risk of developing colorectal cancer, and it had no significant effect on intent, test preference, or uptake. One possible explanation is that the intervention's message that screening is widely employed may have led patients to conclude that colorectal cancer poses a serious risk. We anticipated that viewing the nudge would increase intent to undergo FIT and preference for this test, but we did not find this. In our study, the Basic Information module viewed by all patients explained that FIT is an approved option, so the additional encouragement to choose FIT provided by the nudge module may have had a relatively small effect compared to this more general information

\section{Limitations:}

Our study has several limitations. First, there was limited power to detect effects of the interventions, overall and within sub-groups, due to sample size. It was assumed there would be no change from T0 to T1 in the Basic Info group and no consideration of numeracy in the $a$ priori calculation. Effect sizes obtained from pilot studies should be interpreted with caution and not used as sole evidence to decide whether or not to conduct a larger trial. ${ }^{91}$ Second, we did not adjust for multiple testing. For example, applying a Bonferroni correction to the five main outcomes (adjusted alpha level 0.01), only the two-way interaction of numeracy and quantitative on perceived risk and the main effects for numeracy on colorectal cancer screening intent and decision conflict in Research Question 2 remain significant. Third, we recruited patients from several clinics within a single healthcare system in a single Midwestern city. Fourth, we were unable to confirm screening uptake in the EHR for 15\% of our participants, introducing a possible source of bias in our results. Finally, our quantitative module presented only some quantitative information using certain frames, and the nudge intervention used only some techniques, so other information or other ways of framing the information could have other effects.

Conclusion: This paper reports the effects of adding two separate modules to a decision aid regarding colorectal cancer screening: (1) quantitative information recommended by widely 
accepted guidelines, and (2) a nudge towards stool testing. Most notably, we found that quantitative information significantly increased uptake of screening at six months, while the nudge had no effect on uptake. In addition, we found that quantitative information reduced perceived colorectal cancer risk overall, and this was moderated by numeracy. These findings support further research on the impact of providing quantitative information to patients considering screening, especially given the possibility of increasing uptake of highly recommended and effective screening tests.

\section{Acknowledgments:}

Author contributions:

- Schwartz: Study concept and design, Obtained funding, Acquisition of data, Administrative, technical, or material support, Study supervision, Statistical analysis, Analysis and interpretation of data, Drafting of the manuscript, Critical revision of the manuscript for important intellectual content,

- Perkins: Study concept and design, Statistical analysis, Analysis and interpretation of data, Drafting of the manuscript, Critical revision of the manuscript for important intellectual content,

- Schmidt: Acquisition of data, Administrative, technical, or material support, Study supervision, Statistical analysis, Analysis and interpretation of data, Drafting of the manuscript, Critical revision of the manuscript for important intellectual content,

- Muriello: Acquisition of data, Study supervision, Critical revision of the manuscript for important intellectual content,

- Althouse: Statistical analysis, Analysis and interpretation of data, Drafting of the manuscript, Critical revision of the manuscript for important intellectual content,

- Rawl: Study concept and design, Study supervision, Analysis and interpretation of data, Drafting of the manuscript, Critical revision of the manuscript for important intellectual content.

Financial Disclosure: 
- No author has any commercial associations that might pose a conflict of interest.

- Funding for this research was provided by the American Cancer Society (Cancer Control Career Development Award for Primary Care Physicians (PI: Schwartz)(CCCDA-10085-01)) and an Indiana University Health Values grant (VFR-320) (PI: Schwartz).

- The funding sources had no role in the design, execution, analysis, stopping decision, interpretation, or reporting of this study.

- Drs. Schwartz and Perkins are supported by the Indiana Clinical and Translational Sciences Institute (NCRR 1 UL TR001108-01).

- Dr. Perkins is supported by the Indiana University Simon Cancer Center (NIH P30 CA82709).

Others who have made substantial contributions but who do not fulfill authorship criteria: Thor Peterson, BS, Clinical IS Coordinator - Ambulatory Decision Support, IU Health: Creating and implementing query to identify potentially eligible patients in electronic medical record

\section{REFERENCES:}

1. Stacey D, Bennett CL, Barry MJ, Col NF, Eden KB, Holmes-Rovner M, LlewellynThomas H, Lyddiatt A, Légaré F, Thomson R. Decision aids for people facing health treatment or screening decisions. Cochrane Database Syst Rev. 2012(10).

2. O'Connor AM. Using decision aids to help patients navigate the "grey zone" of medical decision-making. CMAJ. 2007;176(11):1597-1598.

3. O'Connor AM, Wennberg JE, Legare F, Lewllyn-Thomas H, Moulton B, Sepucha K, Sodano A, King J. Toward the 'tipping point': decision aids and informed patient choice. Health affairs (Project Hope). 2007;26(3):716-725.

4. Elwyn G, O'Connor A, Stacey D, Volk R, Edwards A, Coulter A, Thomson R, Barratt A, Barry M, Bernstein S, et al. Developing a quality criteria framework for patient decision aids: online international Delphi consensus process. BMJ. 2006;333(7565):417-423

5. Lee EO, Emanuel EJ. Shared decision making to improve care and reduce costs. New Engl J Med. 2012;368(1):6-8.

6. Barratt A, Trevena L, Davey HM, McCaffery K. Use of decision aids to support informed choices about screening. BMJ. 2004;329(7464):507-510.

7. Trevena L, Zikmund-Fisher B, Edwards A, Gaissmaier W, Galesic M, Han P, King J, Lawson M, Linder S, Lipkus I, et al. Presenting probabilities. In: Volk R, LlewellynThomas H, eds. 2012 Update of the International Patient Decision Aids Standards (IPDAS) Collaboration's Background Document. Chapter C. 2012. Available at http://ipdas.ohri.ca/IPDAS-Chapter-C.pdf Accessed August 4, 2016. 
8. Thornton H, Edwards A, Baum M. Women need better information about routine mammography. BMJ. 2003;327(7406):101-103.

9. Gigerenzer G, Edwards A. Simple tools for understanding risks: from innumeracy to insight. BMJ. 2003;327(7417):741-744.

10. Paling J. Strategies to help patients understand risks. BMJ. 2003;327(7417):745-748.

11. Peters E, Hart PS, Tusler M, Fraenkel L. Numbers matter to informed patient choices: a randomized design across age and numeracy levels. Med Decis Making. 2014;34(4):430442.

12. Sinayev A, Peters E, Tusler M, Fraenkel L. Presenting numeric information with percentages and descriptive risk labels: a randomized trial. Med Decis Making. 2015;35(8):937-947.

13. Trevena LJ, Zikmund-Fisher BJ, Edwards A, Gaissmaier W, Galesic M, Han PKJ, King J, Lawson ML, Linder SK, Lipkus I, Ozanne E, Peters E, Timmermans D, Woloshin S. Presenting quantitative information about decision outcomes: a risk communication primer for patient decision aid developers. BMC Med Inform Decis Mak. 2013;13 Suppl 2:S7.

14. Hawley ST, Zikmund-Fisher B, Ubel P, Jancovic A, Lucas T, Fagerlin A. The impact of the format of graphical presentation on health-related knowledge and treatment choices. Patient Educ Couns. 2008;73(3):448-455.

15. Kutner M, Greenberg E, Jin Y, Paulsen C, Statistics. The health literacy of america's adults: results from the 2003 National Assessment of Adult Literacy. U.S. Department of Education (NCES 2006-483). Washington, DC: National Center for Education;2006.

16. NCES. National Assessment of Adult Literacy (NAAL): Key findings: Demographics: Overall. 2003; http://nces.ed.gov/naal/kf_demographics.asp. Accessed Aug. 4, 2016.

17. Baron J. Thinking and Deciding. 3rd ed. Cambridge: Cambridge University Press; 2000.

18. Reyna VF. How people make decisions that involve risk: a dual-processes approach. Current Directions in Psychological Science. 2004;13(2):60-66.

19. Tversky A, Kahneman D. Judgment under uncertainty: heuristics and biases. Science. 1974;185(4157):1124-1131.

20. Reyna VF. A theory of medical decision making and health: fuzzy trace theory. Med Decis Making. 2008;28(6):850-865.

21. Stacey D, Legare F, Col NF, Bennet CL, Barry MJ, Holmes-Rovner M, LewellynThomas H, Lyddiatt A, Thomson R, et al. Decision aids for people facing health treatment or screening decisions. Cochrane Database Syst Rev. 2014(1).

22. Wolf AMD, Schorling JB. Does informed consent alter elderly patients' preferences for colorectal cancer screening? Results of a randomized trial. Journal of General Internal Medicine. 2000;15(1):24-30.

23. Zikmund-Fisher BJ. The right tool is what they need, not what we have: a taxonomy of appropriate levels of precision in patient risk communication. Med Care Res Rev. 2013;70 (1 Suppl):37S-49S.

24. Ubel PA. The experimental imperative. Hastings Cent Rep. 2011;41(2):3.

25. McDonald H, Charles C, Gafni A. Assessing the conceptual clarity and evidence base of quality criteria/standards developed for evaluating decision aids. Health Expect. 2011.

26. Schwartz PH. Questioning the quantitative imperative: decision aids, prevention, and the ethics of disclosure. Hastings Cent Rep. 2011;41(2):30-39. 
27. Zikmund-Fisher BJ, Fagerlin A, Ubel PA. Risky feelings: why a 6\% risk of cancer does not always feel like 6\%. Patient Educ Couns. 2010;81 Suppl:S87-S93.

28. USPSTF. Screening for colorectal cancer: U.S. Preventive Services Task Force recommendation statement. Ann Intern Med. 2008;149(9):627-637.

29. Levin B, Lieberman DA, McFarland B, Andrews KS, Brooks D, Bond J, Dash C, Giardiello FM, Glick S, Johnson D, et al. Screening and surveillance for the early detection of colorectal cancer and adenomatous polyps, 2008: a joint guideline from the American Cancer Society, the US Multi-Society Task Force on Colorectal Cancer, and the American College of Radiology. Gastroenterology. 2008;134(5):1570-1595.

30. Rex DK, Johnson DA, Anderson JC, Schoenfeld PS, Burke CA, Inadomi JM. American College of Gastroenterology guidelines for colorectal cancer screening 2008. Am J Gastroenterol. 2009;104(3):739-750.

31. Klabunde CN, Joseph DA, King JB, White A, Plescia M. Vital Signs: Colorectal cancer screening test use — United States, 2012. Morbidity and Mortality Weekly Report. 2013;62(44):881-888.

32. Zauber AG, Lansdorp-Vogelaar I, Knudsen AB, Wilschut J, van Ballegooijen M, Kuntz KM. Evaluating test strategies for colorectal cancer screening: a decision analysis for the U.S. Preventive Services Task Force. Ann Intern Med. 2008;149(9):659-669.

33. Heitman SJ, Hilsden RJ, Au F, Dowden S, Manns BJ. Colorectal cancer screening for average-risk North Americans: an economic evaluation. PLoS Med. 2010;7(11):e1000370.

34. Trevena LJ, Irwig L, Barratt A. Randomized trial of a self-administered decision aid for colorectal cancer screening. J Med Screen. 2008;15(2):76-82.

35. Smith SK, Trevena L, Simpson JM, Barratt A, Nutbeam D, McCaffery KJ. A decision aid to support informed choices about bowel cancer screening among adults with low education: randomised controlled trial. BMJ. 2010;341:c5370.

36. Schroy PC, 3rd, Emmons K, Peters E, Glick JT, Robinson PA, Lydotes MA, Mylvanaman S, Evans S, Chaisson C, Pignone M, et al. The impact of a novel computerbased decision aid on shared decision making for colorectal cancer screening: a randomized trial. Med Decis Making. 2011; 31(1): 93-107.

37. Pignone M, Harris R, Kinsinger L. Videotape-based decision aid for colon cancer screening. A randomized, controlled trial. Ann Intern Med. 2000;133(10):761-769.

38. Dolan JG, Frisina S. Randomized controlled trial of a patient decision aid for colorectal cancer screening. Med Decis Making. 2002;22(2):125-139.

39. Ruffin MT, Fetters MD, Jimbo M. Preference-based electronic decision aid to promote colorectal cancer screening: results of a randomized controlled trial. Prev Med. 2007;45(4):267-273.

40. Thaler RH, Sunnstein CR. Nudge: Improving Decisions About Health, Wealth, and Happiness New Haven, CT: Yale University Press; 2008.

41. Johnson EJ, Shu SB, Dellaert BGC, Fox C, Goldstein DG, Häubl G, Larrick RP, Payne JW, Peters E, Schkade D, Wansink B, Weber EU. Beyond nudges: tools of a choice architecture. Marketing Letters. 2012; 23: 487-504.

42. Cialdini RB, Goldstein NJ. Social influence: compliance and conformity. Annu Rev Psychol. 2004;55:591-621. 
43. Schultz PW, Nolan JM, Cialdini RB, Goldstein NJ, Griskevicius V. The constructive, destructive, and reconstructive power of social norms. Psychological Science. 2007; 18(5): 429-434

44. Burchell K, Rettie R, Patel K. Marketing social norms: social marketing and the 'social norm approach'. Journal of Consumer Behaviour. 2013;12:1-9.

45. $\quad$ Ubel PA. "What should I do, doc?": Some psychologic benefits of physician recommendations. Archives of Internal Medicine. 2002;162(9):977-980.

46. Blumenthal-Barby JS, Burroughs H. Seeking better health care outcomes: the ethics of using the "nudge". American Journal of Bioethics : AJOB. 2012;12(2):1-10.

47. Purnell JQ, Thompson T, Kreuter MW, McBride TD. Behavioral economics: "nudging" underserved populations to be screened for cancer. Prev Chronic Dis. 2015;12(E06): 1-9.

48. Inadomi JM, Vijan S, Janz NK, Fagerlin A, Thomas JP, Lin YV, Muñoz R, Lau C, Somsouk M, El-Nachef N, et al. Adherence to colorectal cancer screening a randomized clinical trial of competing strategies. Archives of Internal Medicine. 2012;172(7):575582.

49. Gupta S, Halm EA, Rockey DC, Hammons M, Koch M, Carter E, Valdez L, Tong L, Ahn C, Kashner M, et al. Comparative effectiveness of fecal immunochemical test outreach, colonoscopy outreach, and usual care for boosting colorectal cancer screening among the underserved: a randomized clinical trial. JAMA internal medicine. 2013;173(18):1725-1732.

50. Epstein RM, Alper BS, Quill TE. Communicating evidence for participatory decision making. JAMA. 2004;291(19):2359-2366.

51. Han PK, Lehman TC, Massett H, Lee SJ, Klein WM, Freedman AN. Conceptual problems in laypersons' understanding of individualized cancer risk: a qualitative study. Health Expect. 2009;12(1):4-17.

52. Wilson EA, Wolf MS. Working memory and the design of health materials: a cognitive factors perspective. Patient Education \& Counseling. 2009;74(3):318-322.

53. Ancker JS, Kaufman D. Rethinking health numeracy: a multidisciplinary literature review. J Am Med Inform Assoc. 2007;14(6):713-721.

54. Zikmund-Fisher BJ, Fagerlin A, Ubel PA. A demonstration of "less can be more" in risk graphics. Med Decis Making. 2010;30(6):661-671.

55. Galesic M, Garcia-Retamero R, Gigerenzer G. Using icon arrays to communicate medical risks: Overcoming low numeracy. Health Psychology. 2009;28(2):210-216.

56 Garcia-Retamero R, Galesic M, Gigerenzer G. Do icon arrays help reduce denominator neglect? Medical Decision Making. 2010;30(6):672-684.

57. Halpern SD, Ubel PA, Asch DA. Harnessing the power of default options to improve health care. N Engl J Med. 2007;357(13):1340-1344.

58. Goldstein DG. Nudge your customers toward better choices. Harvard Bus Rev. 2008;86(12):99-105

59. Ling BS, Moskowitz MA, Wachs D, Pearson B, Schroy PC. Attitudes toward colorectal cancer screening tests. J Gen Intern Med. 2001;16(12):822-830.

60. Menon U, Champion VL, Larkin GN, Zollinger TW, Gerde PM, Vernon SW. Beliefs associated with fecal occult blood test and colonoscopy use at a worksite colon cancer screening program. J Occup Environ Med. 2003;45(8):891-898.

61. Sheikh RA, Kapre S, Calof OM, Ward C, Raina A. Screening preferences for colorectal cancer: a patient demographic study. South Med J. 2004;97(3):224-230. 
62. Nelson RL, Schwartz A. A survey of individual preference for colorectal cancer screening technique. BMC Cancer. 2004;4:76.

63. Dolan JG. Patient priorities in colorectal cancer screening decisions. Health Expect. 2005;8(4):334-344.

64. DeBourcy AC, Lichtenberger S, Felton S, Butterfield KT, Ahnen DJ, Denberg TD. Community-based preferences for stool cards versus colonoscopy in colorectal cancer screening. J Gen Intern Med. 2008;23(2):169-174.

65. Marshall DA, Johnson FR, Phillips KA, Marshall JK, Thabane L, Kulin NA. Measuring patient preferences for colorectal cancer screening using a choice-format survey. Value Health. 2007;10(5):415-430.

66. Almog R, Ezra G, Lavi I, Rennert G, Hagoel L. The public prefers fecal occult blood test over colonoscopy for colorectal cancer screening. Eur J Cancer Prev. 2008;17(5):430437.

67. Hawley ST, Volk RJ, Krishnamurthy P, Jibaja-Weiss M, Vernon SW, Kneuper S. Preferences for colorectal cancer screening among racially/ethnically diverse primary care patients. Med Care. 2008;46(9 Suppl 1):S10-16.

68. Ruffin MTt, Creswell JW, Jimbo M, Fetters MD. Factors influencing choices for colorectal cancer screening among previously unscreened African and Caucasian Americans: findings from a triangulation mixed methods investigation. J Community Health. 2009;34(2):79-89.

69. Hol L, de Bekker-Grob EW, van Dam L, Donkers B, Kuipers EJ, Habbema JD, Steverberg EW, van Leerdam ME, Essink-Bot ML. Preferences for colorectal cancer screening strategies: a discrete choice experiment. Br J Cancer. 2010;102(6):972-980.

70. Nayaradou M, Berchi C, Dejardin O, Launoy G. Eliciting population preferences for mass colorectal cancer screening organization. Med Decis Making. 2010;30(2):224-233.

71. van Ballegooijen M, Rutter CM, Knudsen AB, Zauber AG, Savarino JE, LansdorpVogelaar I, Boer R, Feuer EJ, Habbema JD, Kuntz KM. Clarifying differences in natural history between models of screening: The case of colorectal cancer. Medical Decision Making. 2011;31(4):540-549.

72. Kuntz KM, Lansdorp-Vogelaar I, Rutter CM, Knudsen AB, van Bellegooijen M, Savarino JE, Feuer EJ, Zauber AG. A systematic comparison of microsimulation models of colorectal cancer: The role of assumptions about adenoma progression. Medical Decision Making. 2011;31(4):530-539.

73. Pignone M, Ransohoff DF. Cross-model comparisons to improve the value of modeling: The case of colorectal cancer screening. Medical Decision Making. 2011;31(4):524-526.

74. National Cancer Institute. Simulation Models for Colorectal Cancer. http://cisnet.cancer.gov/projections/colorectal/simulation.php. Accessed May 20, 2016.

75. Rutter CM, Knudsen AB, Marsh TL, Doria-Rose VP, Johnson E, Pabiniak C, Kuntz KM, van Ballegooijen M, Zauber AG, Lansdorp-Vogelaar I. Validation of models used to inform colorectal cancer screening guidelines: accuracy and implications. Med Decis Making. 2016;36(5):604-614.

76. Get tested for colon cancer: Here's how. [DVD] American Cancer Society, Inc.; 2008.

77. Jamieson LF, Bass F.M. Adjusted stated intention measures to predict trial purchase of new products: a comparison of models and methods. Journal of Marketing Research. 1989;26(3):336-345. 
78. O'Connor AM. User Manual - Decision Conflict Scale. 2005; http://decisionaid.ohri.ca/docs/develop/User_Manuals/UM_Decisional_Conflict.pdf. Accessed August 4, 2016.

79. Fagerlin A, Zikmund-Fisher BJ, Ubel PA, Jankovic A, Derry HA, Smith DM. Measuring numeracy without a math test: development of the Subjective Numeracy Scale. Medical Decision Making. 2007;27(5):672-680.

80. Zikmund-Fisher BJ, Smith DM, Ubel PA, Fagerlin A. Validation of the Subjective Numeracy Scale: effects of low numeracy on comprehension of risk communications and utility elicitations. Med Decis Making. 2007;27(5):663-671.

81. Fagerlin A, Ubel PA, Smith DM, Zikmund-Fisher BJ. Making numbers matter: present and future research in risk communication. Am J Health Behav. 2007;31 Suppl 1:S47-56.

82. Zikmund-Fisher BJ, Fagerlin A, Ubel PA. What's time got to do with it? Inattention to duration in interpretation of survival graphs. Risk Anal. 2005;25(3):589-595.

83. Ancker JS, Senathirajah Y, Kukafka R, Starren JB. Design features of graphs in health risk communication: a systematic review. J Am Med Inform Assoc. 2006;13(6):608-618.

84. Edwards A, Elwyn G, Covey J, Matthews E, Pill R. Presenting risk information--a review of the effects of "framing" and other manipulations on patient outcomes. Journal of Health Communication. 2001;6(1):61-82.

85. Akl EA, Oxman AD, Herrin J, Vist GE, Terrenato I, Sperati F, Costinuik C, Blank D, Schünemann H. Using alternative statistical formats for presenting risks and risk reductions. The Cochrane Library. 2011(4):1-84.

86. Hoffman RM, Lewis CL, Pignone MP, Couper MP, Barry MJ, Elmore JG, Levin CA, Van Hoewyk J, Zikmund-Fisher BJ. Decision-making processes for breast, colorectal, and prostate cancer screening: the DECISIONS survey. Med Decis Making. 2010;30(5 Suppl):53S-64S.

87. Fagerlin A, Zikmund-Fisher BJ, Ubel PA. How making a risk estimate can change the feel of that risk: shifting attitudes toward breast cancer risk in a general public survey. Patient Education \& Counseling. 2005;57(3):294-299.

88. Peters E. Numeracy and the perception and communication of risk. Ann N Y Acad Sci. 2008;1128:1-7.

89. Nelson W, Reyna VF, Fagerlin A, Lipkus I, Peters E. Clinical implications of numeracy: theory and practice. Ann Behav Med. 2008;35(3):261-274.

90. Reyna VF, Nelson WL, Han PK, Dieckmann NF. How numeracy influences risk comprehension and medical decision making. Psychol Bull. 2009;135(6):943-973.

91. Kraemer HC, Mintz J, Noda A, Tinklenberg J, Yesavage JA. Caution regarding the use of pilot studies to guide power calculations for study proposals. Archives of general psychiatry. 2006;63(5):484-489. 
Table 1. Demographics and T0 Outcomes

\begin{tabular}{|c|c|c|c|c|c|c|}
\hline Category & Value & $\begin{array}{c}\text { Basic Info Only } \\
\quad(n=52)\end{array}$ & $\begin{array}{l}\text { Quantitative } \\
\qquad(N=56)\end{array}$ & $\begin{array}{l}\text { Default } \\
(n=53)\end{array}$ & $\begin{array}{l}\text { Quantitative } \\
\text { + Default } \\
\text { (N=52) }\end{array}$ & p-value \\
\hline Age & mean (SD) & $56.8(7.8)$ & $56.5(7.0)$ & $56.8(7.0)$ & $56.2(7.3)$ & 0.97 \\
\hline Age - below median numeracy & & $58.9(8.7)$ & $57.3(8.2)$ & $57.9(7.8)$ & $56.7(7.2)$ & 0.76 \\
\hline Age - above median numeracy & & $53.5(4.2)$ & $55.9(5.9)$ & $55.6(6.0)$ & $55.6(7.4)$ & 0.55 \\
\hline \multirow[t]{2}{*}{ Gender } & Female & $34(65 \%)$ & $36(64 \%)$ & $34(64 \%)$ & $36(69 \%)$ & 0.94 \\
\hline & Male & $18(35 \%)$ & $20(36 \%)$ & $19(36 \%)$ & $16(31 \%)$ & \\
\hline \multirow[t]{3}{*}{ Race } & White & $37(71 \%)$ & $42(75 \%)$ & $38(72 \%)$ & $39(75 \%)$ & 0.84 \\
\hline & Black or African American & $12(23 \%)$ & $11(20 \%)$ & $11(21 \%)$ & $12(23 \%)$ & \\
\hline & Other & $2(4 \%)$ & $3(5 \%)$ & $2(4 \%)$ & $0(0 \%)$ & \\
\hline \multirow[t]{3}{*}{ Education } & High school graduate/GED or less & $15(29 \%)$ & $12(21 \%)$ & $9(17 \%)$ & $12(23 \%)$ & 0.77 \\
\hline & $\begin{array}{l}\text { Some college/technical } \\
\text { school/trade school }\end{array}$ & $13(25 \%)$ & $15(27 \%)$ & $18(34 \%)$ & $17(33 \%)$ & \\
\hline & College Graduate or higher & $22(42 \%)$ & $29(52 \%)$ & $26(49 \%)$ & $23(44 \%)$ & \\
\hline \multirow[t]{4}{*}{ Income Level } & $<\$ 20,000$ & $4(8 \%)$ & $7(13 \%)$ & $7(13 \%)$ & $3(6 \%)$ & 0.70 \\
\hline & $\$ 20,000-\$ 39,999$ & $11(21 \%)$ & $8(14 \%)$ & $11(21 \%)$ & $8(15 \%)$ & \\
\hline & $\$ 40,000-\$ 59,999$ & $11(21 \%)$ & $13(23 \%)$ & $12(23 \%)$ & $10(19 \%)$ & \\
\hline & $>=\$ 60,000$ & $16(31 \%)$ & $24(43 \%)$ & $17(32 \%)$ & $26(50 \%)$ & \\
\hline Perceived CRC Risk & mean (SD) & $3.26(1.61)$ & $2.93(1.32)$ & $2.96(1.60)$ & $2.83(1.13)$ & 0.46 \\
\hline CRC Screening Interest & mean (SD) & $3.25(1.15)$ & $3.59(1.11)$ & $3.58(1.08)$ & $3.54(1.09)$ & 0.34 \\
\hline Colonoscopy Interest & mean (SD) & $3.13(1.17)$ & $3.30(1.13)$ & $3.36(1.21)$ & 3.35 (1.19) & 0.75 \\
\hline Fit Interest & mean (SD) & $2.65(0.90)$ & $2.95(1.02)$ & $2.94(1.03)$ & $2.85(0.92)$ & 0.37 \\
\hline Decision Conflict & mean (SD) & $27.7(10.7)$ & $28.8(12.8)$ & $11.5(8.26)$ & $25.7(11.7)$ & 0.29 \\
\hline
\end{tabular}


Table 2. Between Group Differences in change in Intent, Perceived Risk, and Decision Conflict:

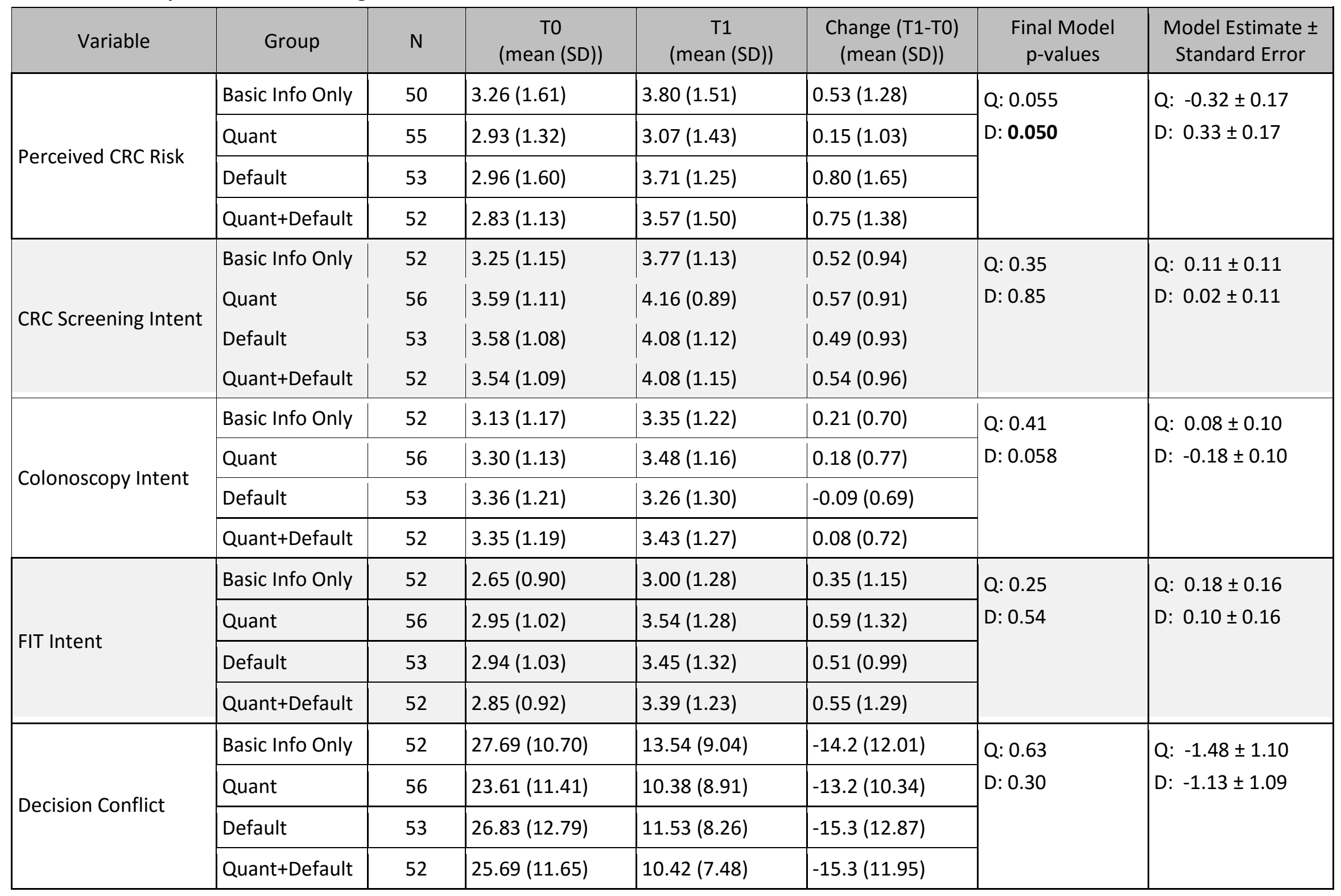

$\mathrm{Q}=$ Quantitative, $\mathrm{D}=$ Default 
Table 3: Test preference before and after intervention:

\begin{tabular}{|c|c|c|c|c|}
\hline \multirow{2}{*}{ Group } & \multicolumn{3}{|c|}{ Intend to be screened with } & \multirow{2}{*}{$\begin{array}{l}\text { Do not intend } \\
\text { to be screened }\end{array}$} \\
\hline & Colonoscopy & Stool Testing (FIT) & Don't Know/Other* & \\
\hline \multicolumn{5}{|l|}{ Basic Info Only ( $n=52)$} \\
\hline Before intervention (T0) & $14(27 \%)$ & $5(10 \%)$ & $4(8 \%)$ & $29(56 \%)$ \\
\hline After intervention (T1) & $19(37 \%)$ & $12(23 \%)$ & $1(2 \%)$ & $20(39 \%)$ \\
\hline \multicolumn{5}{|l|}{ Quantitative $(n=56)$} \\
\hline Before intervention (T0) & $19(34 \%)$ & $8(14 \%)$ & $2(4 \%)$ & $27(48 \%)$ \\
\hline After intervention (T1) & $23(41 \%)$ & $19(34 \%)$ & $4(7 \%)$ & $10(18 \%)$ \\
\hline \multicolumn{5}{|l|}{ Default ( $n=53$ ) } \\
\hline Before intervention (T0) & $20(38 \%)$ & $4(8 \%)$ & $4(8 \%)$ & $25(47 \%)$ \\
\hline After intervention (T1) & $15(28 \%)$ & $24(45 \%)$ & $0(0 \%)$ & $14(26 \%)$ \\
\hline \multicolumn{5}{|c|}{ Quantitative + Default ( $n=52)$} \\
\hline Before intervention (T0) & $20(39 \%)$ & $4(8 \%)$ & $4(8 \%)$ & $24(46 \%)$ \\
\hline After intervention (T1) & $18(35 \%)$ & $17(33 \%)$ & $3 *(6 \%)$ & $14(27 \%)$ \\
\hline
\end{tabular}

*One participant said other at this time point 
Table 4: Changes in test preference from T0 to T1:

\begin{tabular}{|c|c|c|c|c|c|c|}
\hline \multirow{2}{*}{ Group } & \multicolumn{3}{|c|}{ Change in Preference } & \multicolumn{3}{|c|}{ Change from not FIT to FIT } \\
\hline & Overall & $\begin{array}{l}\text { Low } \\
\text { Numeracy }\end{array}$ & $\begin{array}{c}\text { High } \\
\text { Numeracy }\end{array}$ & Overall & $\begin{array}{c}\text { Low } \\
\text { Numeracy }\end{array}$ & $\begin{array}{c}\text { High } \\
\text { Numeracy }\end{array}$ \\
\hline Basic Info Only & $19 / 52(37 \%)$ & $10 / 32$ (31\%) & $8 / 19(42 \%)$ & $10 / 47(21 \%)$ & $5 / 28(18 \%)$ & $5 / 18(28 \%)$ \\
\hline Quantitative & $28 / 56(50 \%)$ & $13 / 24(54 \%)$ & $15 / 32(47 \%)$ & $14 / 48(29 \%)$ & $6 / 20(30 \%)$ & $8 / 28(29 \%)$ \\
\hline Default & $25 / 53(47 \%)$ & $10 / 28(36 \%)$ & $15 / 25(60 \%)$ & $21 / 49(43 \%)$ & $7 / 26(27 \%)$ & $14 / 23(61 \%)$ \\
\hline Quantitative + Default & $21 / 52(40 \%)$ & $10 / 26(39 \%)$ & $11 / 26(42 \%)$ & $15 / 48(31 \%)$ & $7 / 25(28 \%)$ & $8 / 23(35 \%)$ \\
\hline p-value for group comparison & 0.48 & 0.35 & 0.56 & 0.148 & 0.76 & 0.070 \\
\hline
\end{tabular}


Table 5: CRC Uptake by Group and Numeracy Level

\begin{tabular}{|c|c|c|c|c|c|c|c|c|}
\hline & Variable & $\begin{array}{l}\text { Basic Info } \\
\text { Only } \\
\text { n/N (\%) }\end{array}$ & $\begin{array}{c}\text { Quantitative } \\
\mathrm{n} / \mathrm{N}(\%)\end{array}$ & $\begin{array}{l}\text { Default } \\
\text { n/N (\%) }\end{array}$ & $\begin{array}{c}\text { Default + } \\
\text { Quantitative } \\
\mathrm{n} / \mathrm{N}(\%)\end{array}$ & $\begin{array}{c}\text { Final Model } \\
p \text {-values }\end{array}$ & $\begin{array}{c}\text { MLE } \pm \text { Standard } \\
\text { Error }\end{array}$ & Odds Ratio (95\% Cl) \\
\hline Overall & FIT uptake & $5 / 52(10 \%)$ & $7 / 56(13 \%)$ & 6/53 (11\%) & 10/51 (20\%) & $\begin{array}{l}\text { Q: } \\
0.24 \\
\text { D: } 0.34\end{array}$ & $\begin{array}{ll}Q: & 0.49 \pm 0.42 \\
D: & 0.39 \pm 0.41\end{array}$ & $\begin{array}{l}\text { Q: } 1.64(0.73,3.69) \\
D: 1.48(0.66,3.31)\end{array}$ \\
\hline \multirow{2}{*}{$\begin{array}{l}\text { Below Total } \\
\text { Numeracy } \\
\text { Median }\end{array}$} & $\begin{array}{l}\text { CRC screening } \\
\text { uptake }\end{array}$ & $8 / 32(25 \%)$ & $10 / 24(42 \%)$ & $9 / 28(32 \%)$ & $10 / 25$ (40\%) & $\begin{array}{l}\text { Q: } 0.017 \\
\text { D: } 0.41 \\
\text { NM: } 0.72\end{array}$ & $\begin{array}{l}\text { Q: } 0.70 \pm 0.30 \\
\text { D: } 0.24 \pm 0.29 \\
\text { NM: } 0.11 \pm 0.29\end{array}$ & $\begin{array}{l}\text { Q: } 2.02(1.13,3.61) \\
\text { D: } 1.27(0.72,2.25) \\
\text { NM: } 1.11(0.63,7.97)\end{array}$ \\
\hline & $\begin{array}{l}\text { Colonoscopy } \\
\text { uptake }\end{array}$ & $4 / 32(13 \%)$ & $7 / 24(29 \%)$ & $6 / 28(21 \%)$ & $6 / 25$ (24\%) & $\begin{array}{l}\text { Q: } 0.126 \\
\text { D: } 1.000 \\
\text { NM: } 0.37\end{array}$ & $\begin{array}{l}\text { Q: } 0.51 \pm 0.34 \\
\text { D: } 0.001 \pm 0.32 \\
\text { NM: } 0.29 \pm 0.33\end{array}$ & $\begin{array}{l}\text { Q: } 1.66(0.87,3.17) \\
\text { D: } 1.00(0.53,1.89) \\
\text { NM: } 1.34(0.71,2.54)\end{array}$ \\
\hline \multirow{3}{*}{$\begin{array}{l}\text { Above Total } \\
\text { Numeracy } \\
\text { Median }\end{array}$} & $\begin{array}{l}\text { CRC screening } \\
\text { uptake }\end{array}$ & $6 / 19$ (32\%) & $12 / 32(38 \%)$ & $6 / 25$ (24\%) & $15 / 26(58 \%)$ & & & \\
\hline & FIT uptake & $0 / 19(0 \%)$ & $4 / 32(13 \%)$ & $2 / 25(8 \%)$ & $6 / 26(23 \%)$ & & & \\
\hline & $\begin{array}{l}\text { Colonoscopy } \\
\text { uptake }\end{array}$ & $6 / 19$ (32\%) & $9 / 32(28 \%)$ & $4 / 25(16 \%)$ & $9 / 26(35 \%)$ & & & \\
\hline
\end{tabular}

${ }^{*} \mathrm{n}=$ number screened; $\mathrm{N}=$ Total $\mathrm{N}$

$\mathrm{Q}=$ Quantitative, $\mathrm{D}=$ Default, $\mathrm{NM}=$ Numeracy 
Table 6. Between Group Differences in change in Intent, Perceived Risk, and Decision Conflict by numeracy (above/below the median):

\begin{tabular}{|c|c|c|c|c|c|c|c|c|}
\hline Variable & $\begin{array}{l}\text { Numeracy } \\
\text { Category }\end{array}$ & Group & $\mathrm{n}$ & $\begin{array}{c}\text { T0 } \\
\text { (mean (SD)) }\end{array}$ & $\begin{array}{c}\mathrm{T} 1 \\
\text { (mean (SD)) }\end{array}$ & $\begin{array}{l}\text { Change (T1-T0) } \\
\text { (mean (SD)) }\end{array}$ & $\begin{array}{c}\text { Final Model } \\
p \text {-values }\end{array}$ & $\begin{array}{c}\text { Model Estimate } \pm \text { Standard } \\
\text { Error }\end{array}$ \\
\hline \multirow{8}{*}{ Perceived CRC Risk } & \multirow{4}{*}{ Below Median } & Basic Info Only & 31 & $3.71(1.66)$ & $4.06(1.41)$ & $0.33(1.03)$ & \multirow{8}{*}{$\begin{array}{l}\text { Q: } 0.069 \\
\text { D: } 0.075 \\
\text { NM: } 0.118 \\
N^{*} Q: \quad 0.004\end{array}$} & \multirow{8}{*}{$\begin{array}{l}\text { Interaction: } \\
Q \text { for Low NM: } \\
0.18 \pm 0.23(p=0.43) \\
Q \text { for High NM: } \\
-0.79 \pm 0.26(p=0.001)\end{array}$} \\
\hline & & Quant & 23 & $2.96(1.43)$ & $3.43(1.56)$ & $0.48(1.04)$ & & \\
\hline & & Default & 28 & $2.96(1.77)$ & $3.42(1.39)$ & $0.58(2.00)$ & & \\
\hline & & Quant+Default & 26 & $2.81(1.36)$ & $4.00(1.50)$ & $1.20(1.55)$ & & \\
\hline & \multirow{4}{*}{ Above Median } & Basic Info Only & 19 & $2.53(1.26)$ & $3.37(1.64)$ & $0.84(1.57)$ & & \\
\hline & & Quant & 32 & $2.91(1.25)$ & $2.81(1.28)$ & $-0.09(0.96)$ & & \\
\hline & & Default & 25 & $2.96(1.43)$ & $4.00(1.04)$ & $1.04(1.17)$ & & \\
\hline & & Quant+Default & 26 & $2.85(0.88)$ & $3.15(1.41)$ & $0.31(1.05)$ & & \\
\hline \multirow{8}{*}{ CRC Screening Intent } & \multirow{4}{*}{ Below Median } & Basic Info Only & 32 & $3.00(1.14)$ & $3.53(1.19)$ & $0.53(1.02)$ & \multirow{8}{*}{$\begin{array}{l}\text { Q: } 0.62 \\
\text { D: } 0.95 \\
\text { NM: } \mathbf{0 . 0 0 2}\end{array}$} & \multirow{8}{*}{$\begin{array}{l}\text { Q: } 0.06 \pm 0.11 \\
\text { D: } 0.01 \pm 0.11 \\
\text { NM: } 0.36 \pm 0.11\end{array}$} \\
\hline & & Quant & 24 & $3.75(1.07)$ & $4.13(0.95)$ & $0.38(1.01)$ & & \\
\hline & & Default & 28 & $3.50(1.11)$ & $3.71(1.30)$ & $0.21(0.88)$ & & \\
\hline & & Quant+Default & 26 & $3.35(1.20)$ & $3.85(1.26)$ & $0.50(0.71)$ & & \\
\hline & \multirow{4}{*}{ Above Median } & Basic Info Only & 19 & $3.63(1.12)$ & $4.21(0.92)$ & $0.58(0.77)$ & & \\
\hline & & Quant & 32 & $3.47(1.14)$ & $4.19(0.86)$ & $0.72(0.81)$ & & \\
\hline & & Default & 25 & $3.68(1.07)$ & $4.48(0.71)$ & $0.80(0.91)$ & & \\
\hline & & Quant+Default & 26 & $3.73(0.96)$ & $4.31(1.01)$ & $0.58(1.17)$ & & \\
\hline \multirow{8}{*}{ Colonoscopy Intent } & \multirow{4}{*}{ Below Median } & Basic Info Only & 32 & $2.88(1.16)$ & $3.16(1.11)$ & $0.28(0.58)$ & \multirow{8}{*}{$\begin{array}{l}\text { Q: } 0.46 \\
\text { D: } 0.046 \\
\text { NM: } 0.78\end{array}$} & \multirow{8}{*}{$\begin{array}{l}\text { Q: } 0.72 \pm 0.10 \\
\text { D: }-0.19 \pm 0.10 \\
\text { NM: }-0.02 \pm 0.10\end{array}$} \\
\hline & & Quant & 24 & $3.42(1.06)$ & $3.54(1.10)$ & $0.13(0.74)$ & & \\
\hline & & Default & 28 & $3.36(1.28)$ & $3.36(1.39)$ & $0.00(0.61)$ & & \\
\hline & & Quant+Default & 26 & $3.27(1.25)$ & $3.32(1.31)$ & $0.04(0.73)$ & & \\
\hline & \multirow{4}{*}{ Above Median } & Basic Info Only & 19 & $3.53(1.12)$ & $3.68(1.38)$ & $0.16(0.83)$ & & \\
\hline & & Quant & 32 & $3.22(1.18)$ & $3.44(1.22)$ & $0.22(0.79)$ & & \\
\hline & & Default & 25 & $3.36(1.15)$ & $3.16(1.21)$ & $-0.20(0.76)$ & & \\
\hline & & Quant+Default & 26 & $3.42(1.14)$ & $3.54(1.24)$ & $0.12(0.71)$ & & \\
\hline
\end{tabular}




\begin{tabular}{|c|c|c|c|c|c|c|c|c|}
\hline Variable & $\begin{array}{l}\text { Numeracy } \\
\text { Category }\end{array}$ & Group & $n$ & $\begin{array}{c}\text { T0 } \\
(\text { mean }(S D))\end{array}$ & $\begin{array}{c}\mathrm{T} 1 \\
\text { (mean (SD)) }\end{array}$ & $\begin{array}{l}\text { Change (T1-T0) } \\
\text { (mean (SD)) }\end{array}$ & $\begin{array}{l}\text { Final Model } \\
p \text {-values }\end{array}$ & $\begin{array}{c}\text { Model Estimate } \pm \text { Standard } \\
\text { Error }\end{array}$ \\
\hline \multirow{8}{*}{ FIT Intent } & \multirow{4}{*}{ Below Median } & Basic Info Only & 32 & $2.66(0.97)$ & $3.00(1.32)$ & $0.34(1.26)$ & \multirow{8}{*}{$\begin{array}{l}Q: 0.33 \\
D: 0.37 \\
N M: 0.059 \\
N M^{*} Q: 0.84 \\
N{ }^{*} D: 0.80 \\
Q^{*} N D: 0.30 \\
N M^{*} Q^{*} D: \\
\mathbf{0 . 0 2 5}\end{array}$} & \multirow{8}{*}{$\begin{array}{l}\text { Interaction: } \\
Q \text { for Low NM, No D: } \\
-0.07 \pm 0.31(p=0.81) \\
Q \text { for Low NM, Yes D: } \\
0.32 \pm 0.31(p=0.31) \\
Q \text { for High NM, No D: } \\
0.71 \pm 0.33(p=0.030) \\
Q \text { for High NM, Yes } D \text { : } \\
-0.34 \pm 0.32(p=0.29)\end{array}$} \\
\hline & & Quant & 24 & $3.21(1.14)$ & $3.29(1.30)$ & $0.08(1.21)$ & & \\
\hline & & Default & 28 & 3.11 (0.99) & $3.29(1.24)$ & $0.18(0.82)$ & & \\
\hline & & Quant+Default & 26 & $2.69(0.97)$ & $3.32(1.31)$ & $0.64(1.38)$ & & \\
\hline & \multirow{4}{*}{ Above Median } & Basic Info Only & 19 & $2.74(0.73)$ & $3.00(1.29)$ & $0.26(0.93)$ & & \\
\hline & & Quant & 32 & $2.75(0.88)$ & $3.72(1.25)$ & $0.97(1.28)$ & & \\
\hline & & Default & 25 & $2.76(1.05)$ & $3.64(1.41)$ & $0.88(1.05)$ & & \\
\hline & & Quant+Default & 26 & $3.00(0.85)$ & $3.46(1.17)$ & $0.46(1.21)$ & & \\
\hline \multirow{8}{*}{ Decision Conflict } & \multirow{4}{*}{ Below Median } & Basic Info Only & 32 & $29.59(11.73)$ & $16.06(7.26)$ & $-13.5(12.46)$ & \multirow{8}{*}{$\begin{array}{l}\text { Q: } 0.42 \\
\text { D: } 0.39 \\
\text { NM: }<\mathbf{0 . 0 0 1}\end{array}$} & \multirow{8}{*}{$\begin{array}{l}\text { Q: }-0.86 \pm 1.06 \\
\text { D: }-0.90 \pm 1.05 \\
\text { NM: }-4.06 \pm 1.05\end{array}$} \\
\hline & & Quant & 24 & $23.50(10.93)$ & $11.04(9.88)$ & $-12.5(9.67)$ & & \\
\hline & & Default & 28 & $25.11(9.60)$ & $13.68(8.50)$ & $-11.4(9.10)$ & & \\
\hline & & Quant+Default & 26 & 25.77 (10.93) & $12.15(7.29)$ & $-13.6(10.83)$ & & \\
\hline & \multirow{4}{*}{ Above Median } & Basic Info Only & 19 & $24.26(8.20)$ & $8.32(9.02)$ & $-15.9(11.22)$ & & \\
\hline & & Quant & 32 & 23.69 (11.94) & $9.88(8.24)$ & $-13.8(10.93)$ & & \\
\hline & & Default & 25 & $28.76(15.61)$ & $9.12(7.42)$ & $-19.6(15.11)$ & & \\
\hline & & Quant+Default & 26 & $25.62(12.55)$ & 8.69 (7.39) & $-16.9(12.98)$ & & \\
\hline
\end{tabular}

$\mathrm{Q}=$ Quantitative, $\mathrm{ND}=$ Default, $\mathrm{NM}=$ Numeracy 
figure 1. Randomized controlled trial with $2 \times 2$ design

\begin{tabular}{llcl} 
& \multicolumn{3}{c}{ Nudge } \\
& & No & Yes \\
$\begin{array}{l}\text { Quantitative } \\
\text { Information }\end{array}$ & Bosic Info Only & Nudge \\
& Yes & Quantitative & $\begin{array}{l}\text { Quantitative + } \\
\text { Nudge }\end{array}$
\end{tabular}


figure 2. Research process diagram

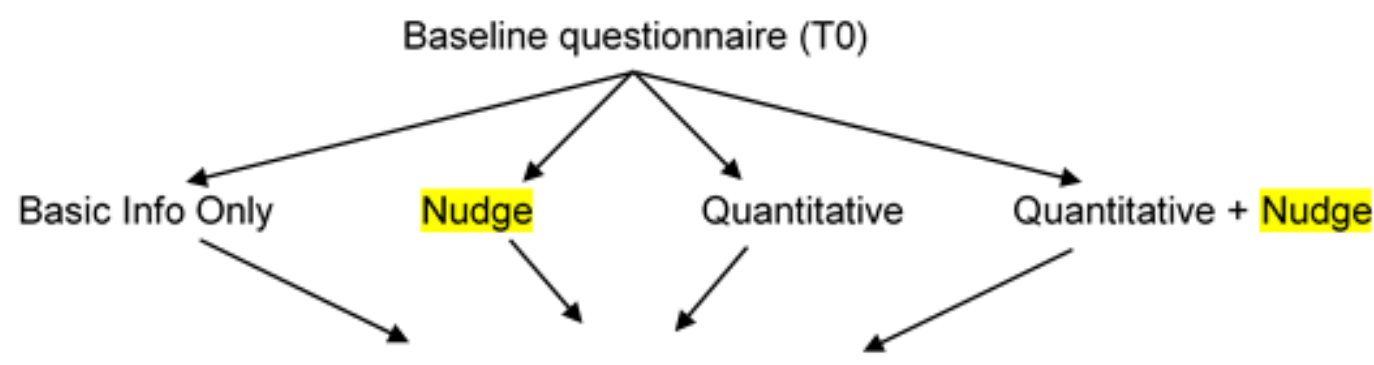

Post-intervention questionnaire (T1)

Six-month follow-up call (T2) and EMR check 
figure 3. Study flow diagram of recruitment and follow-up

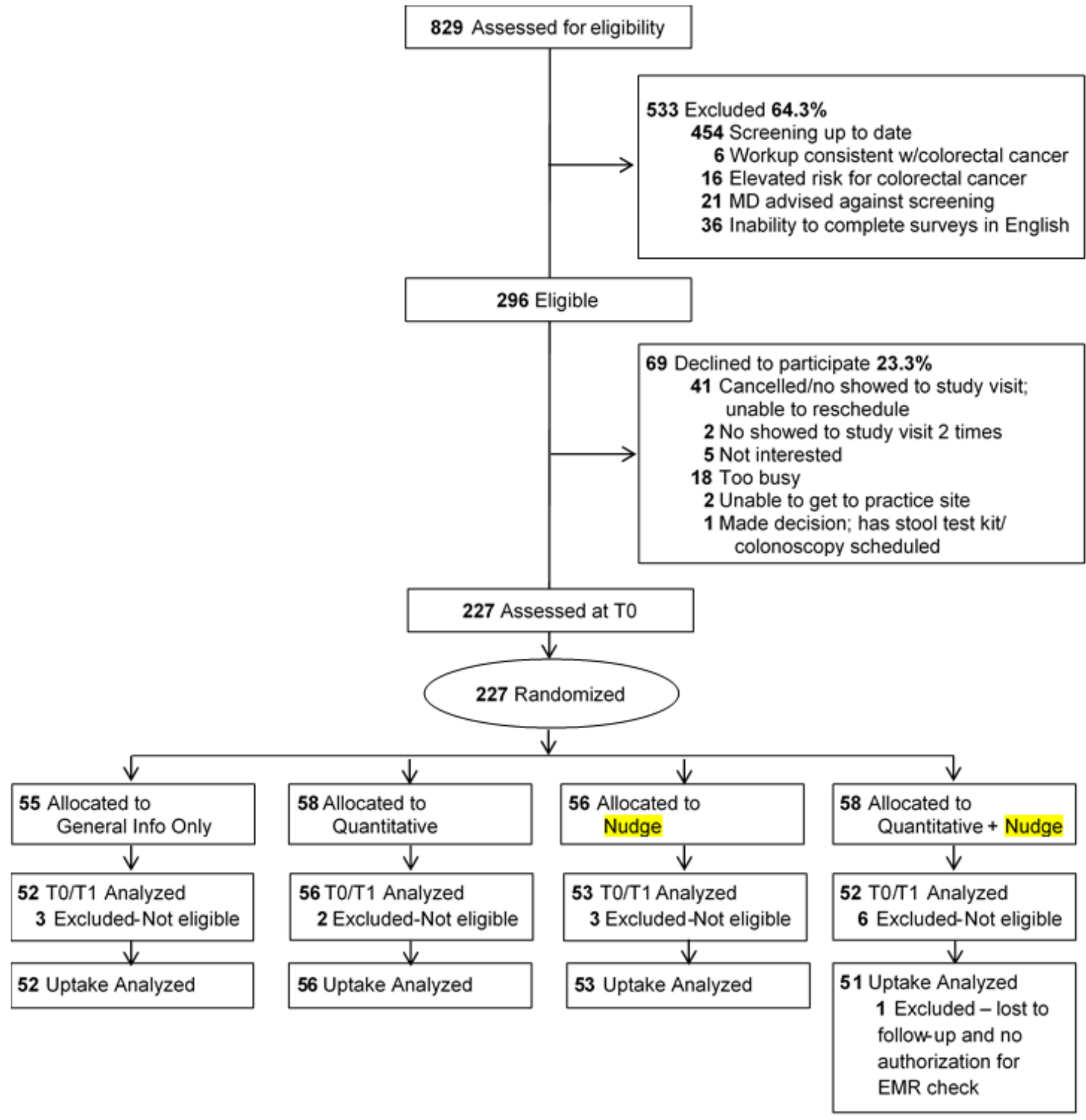




\section{Appendix: Sample Slides and Audio Tracks}

Basic Information Only Module: Slides reiterating pros and cons of colonoscopy and stool testing presented by an American Cancer Society video presented earlier in the module:

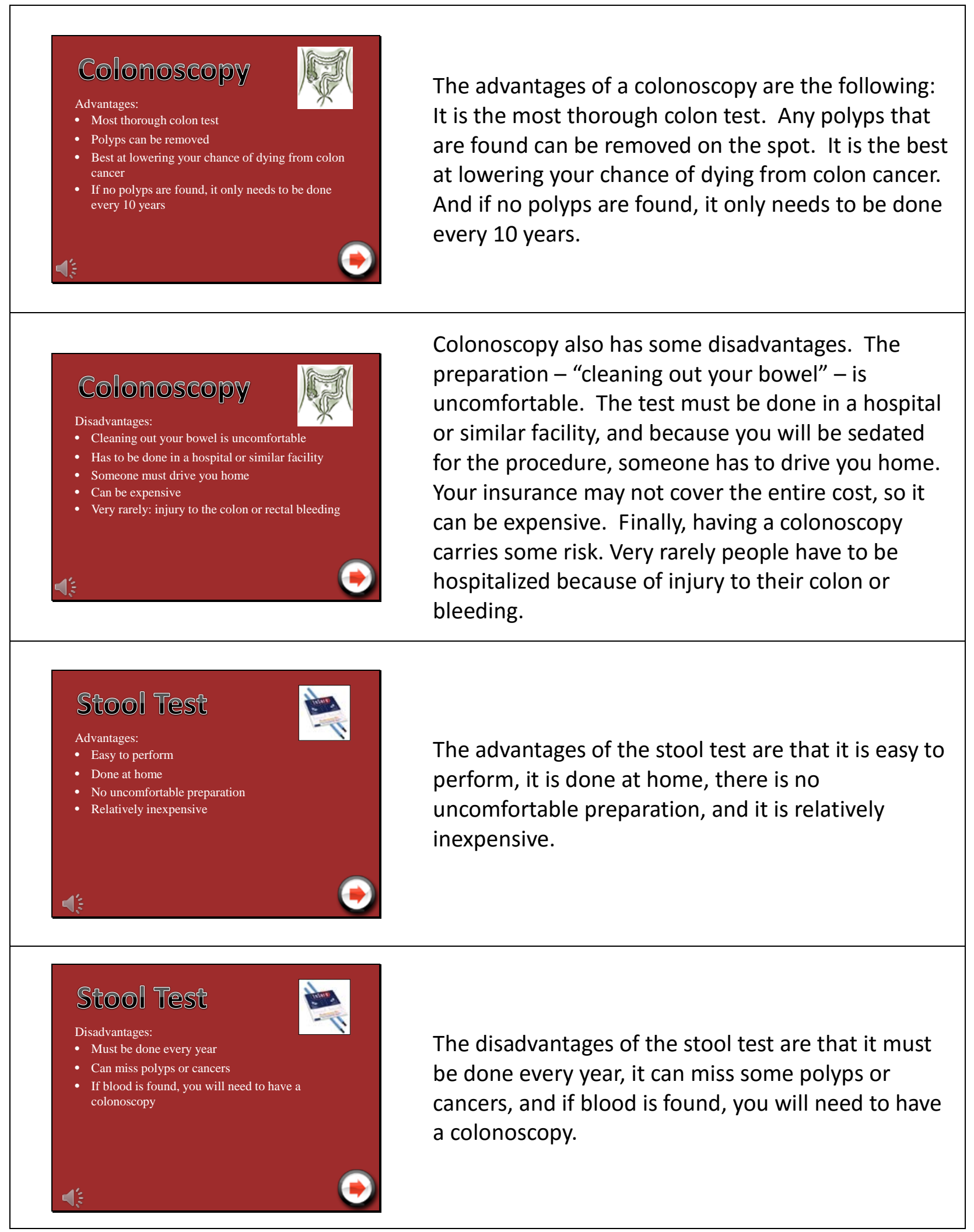


Quantitative Module: No screening

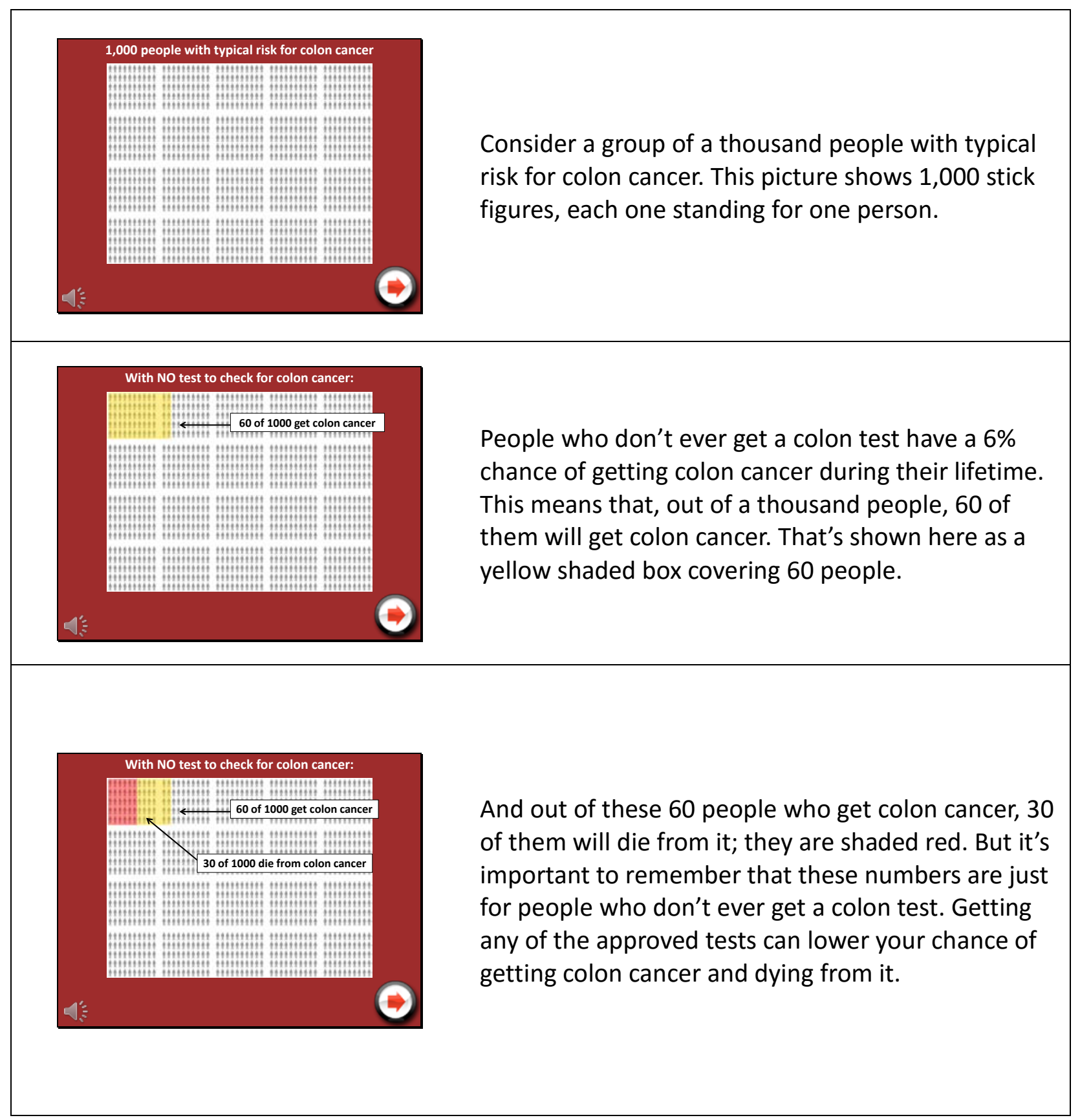


Quantitative Module: Colonoscopy

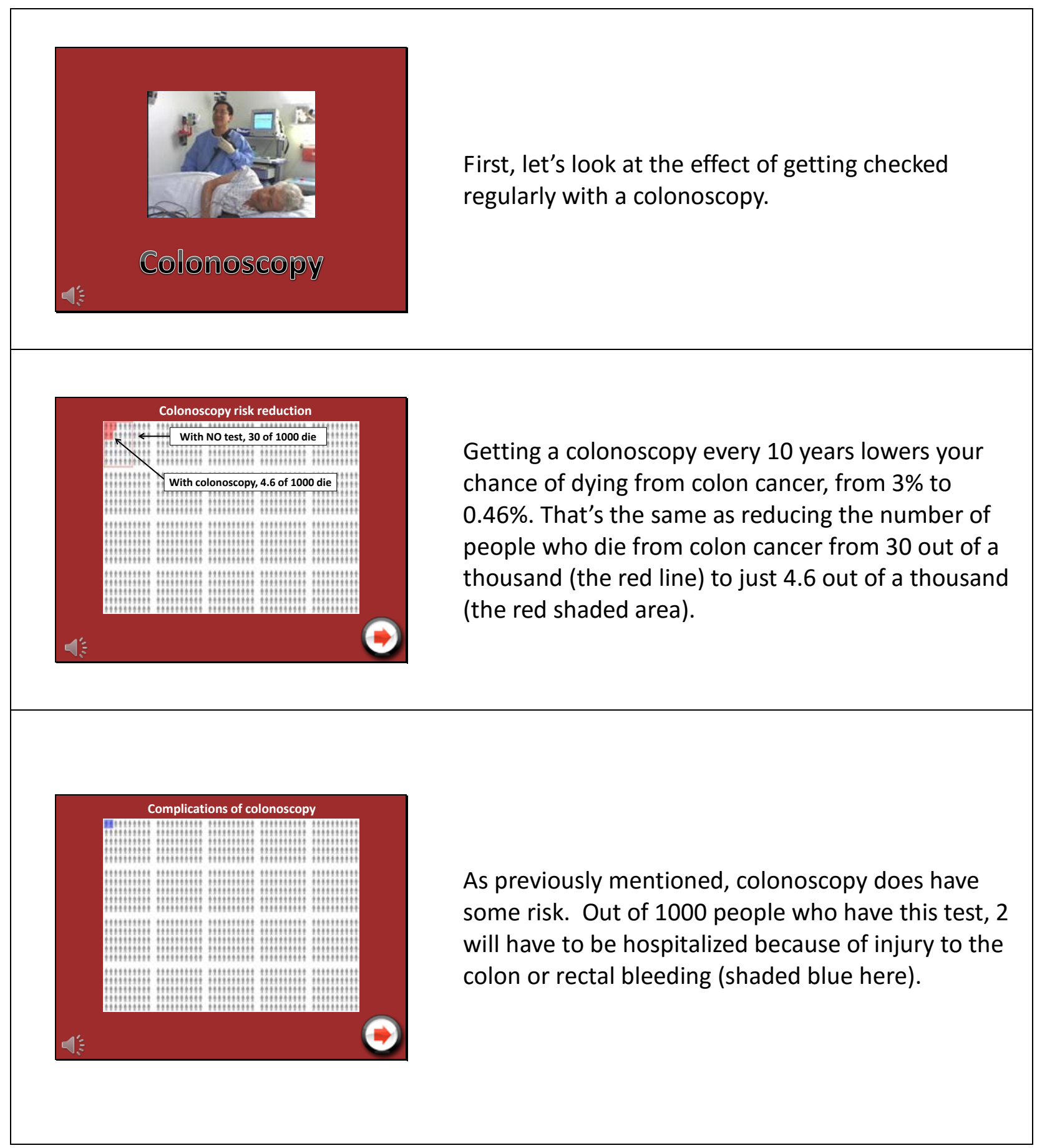


Quantitative Module: Stool test and bar chart.

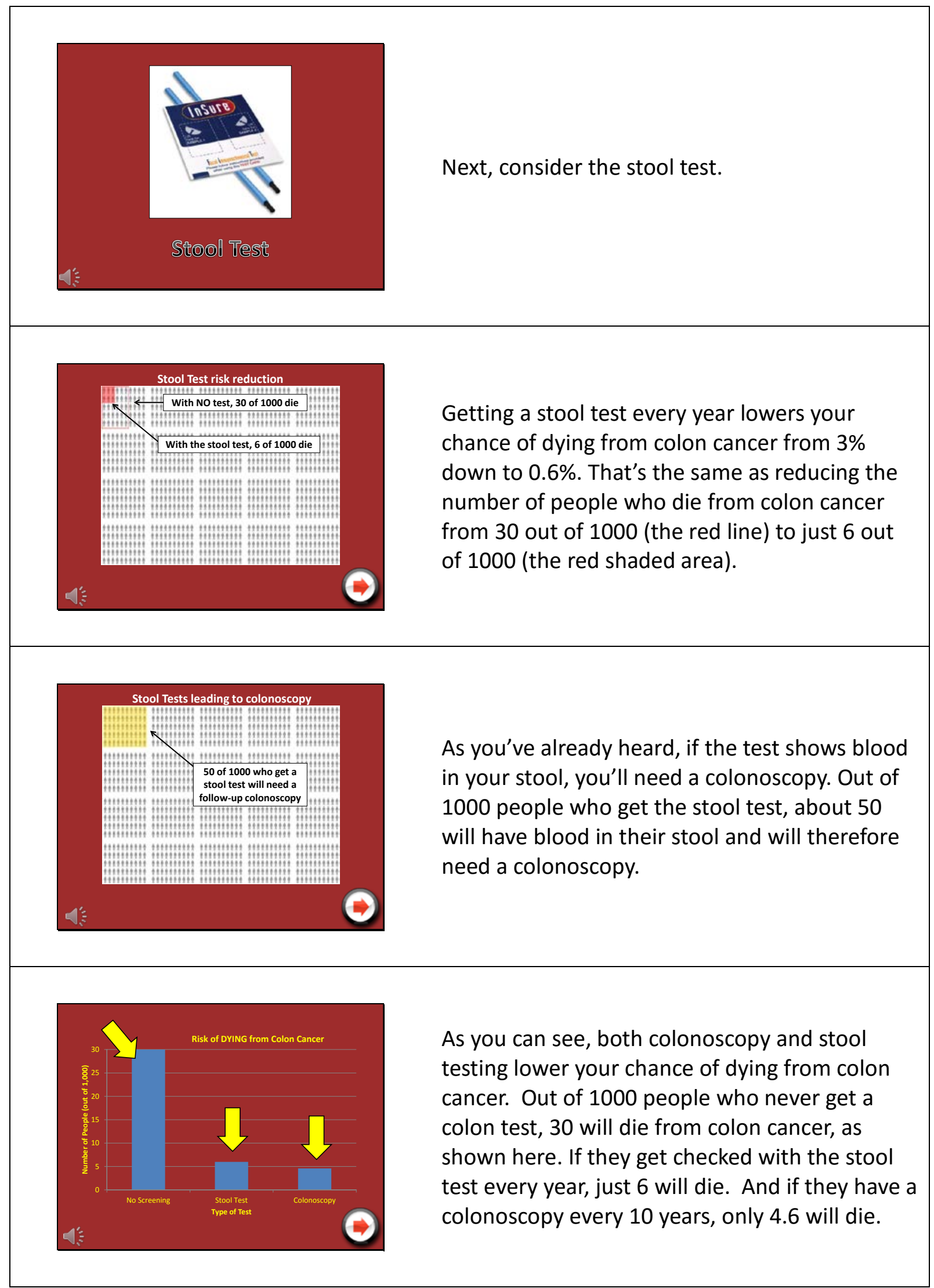




\section{Nudge Module:}

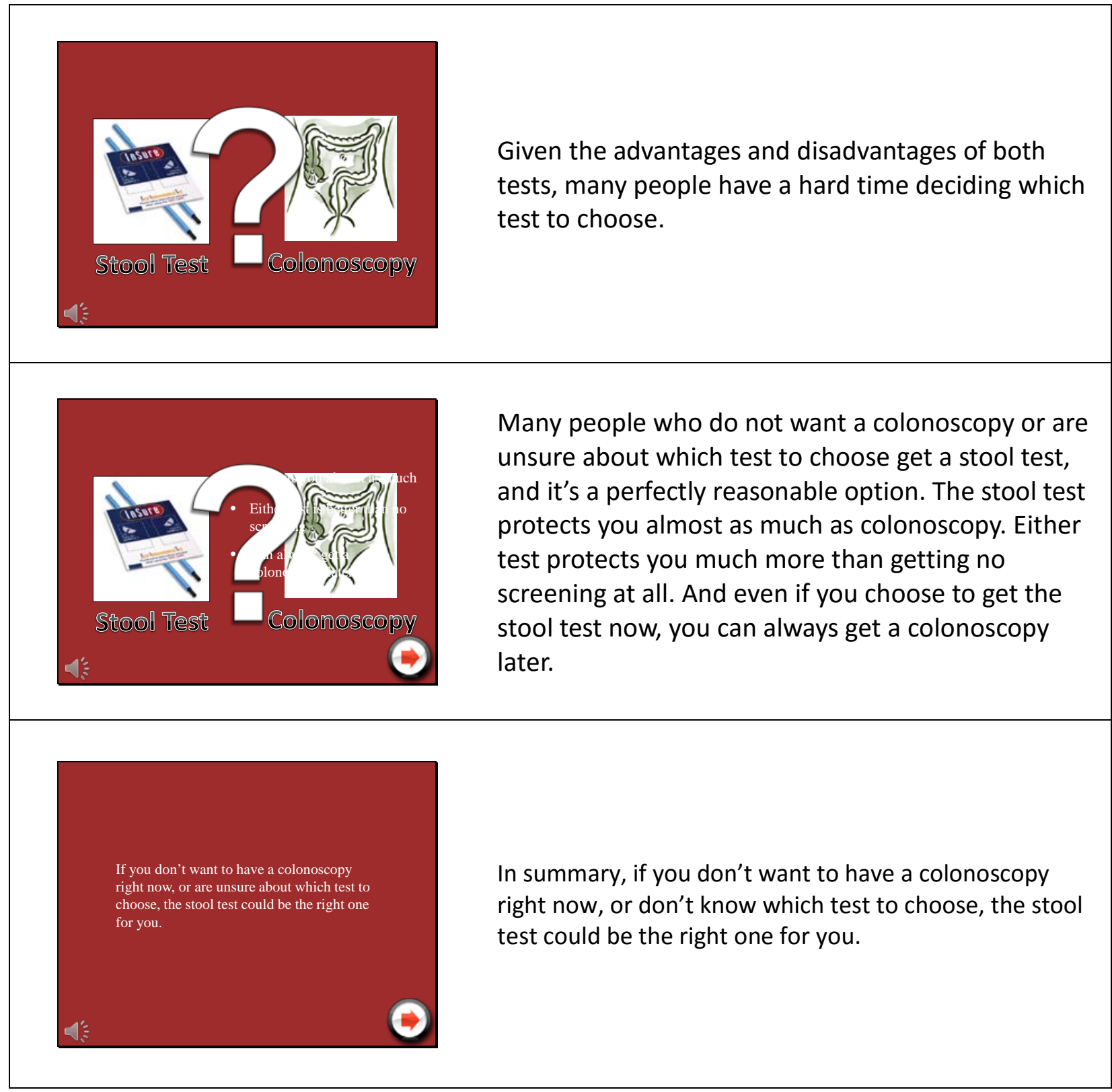

All modules: Conclusion slide

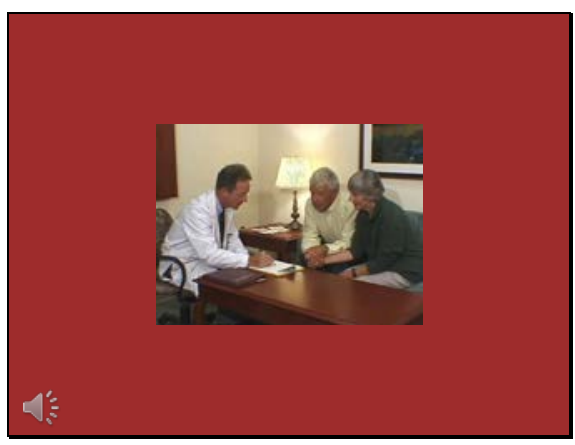

Your doctor may recommend a particular test, but the decision is yours to make. In the end, what really matters is that you make a decision that's right for you. 
Figure S1. Change in Perceived CRC Risk and Decision Conflict from T0 to T1 (Mean \pm SE)

Perceived CRC risk at T0 and T1 for: a: all participants; b: patients with low numeracy; c: patients with high numeracy.
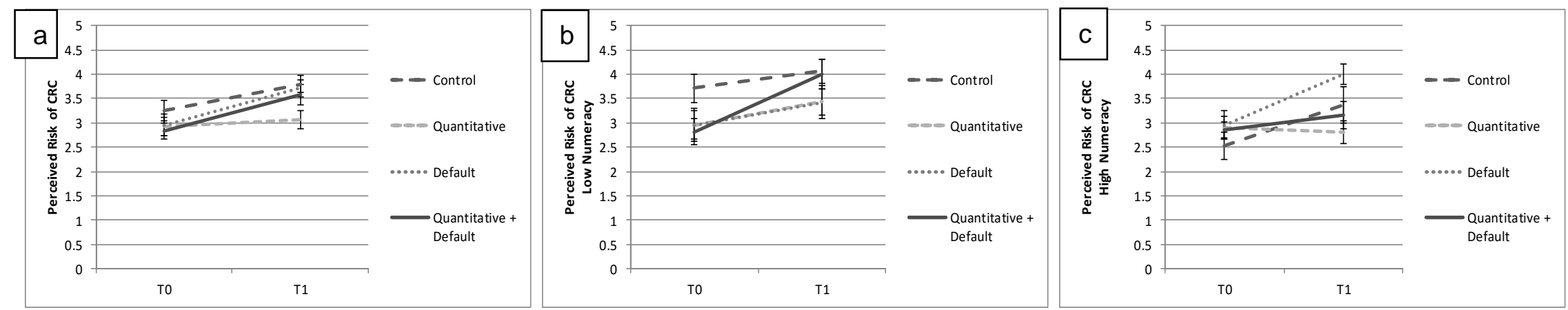

Decision conflict at T0 and T1 for: $\mathbf{d}$ : all participants; e: patients with low numeracy; f: patients with high numeracy.
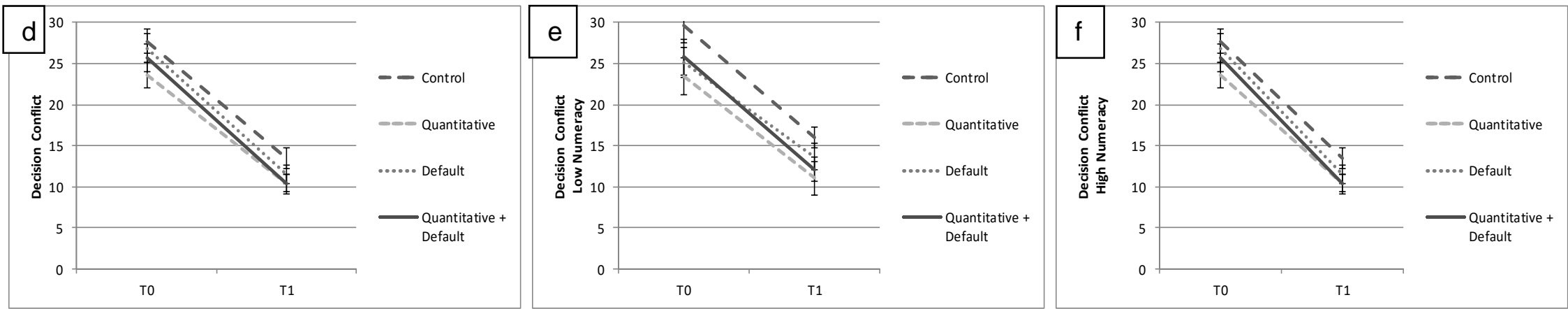
Figure S2. Change in CRC Screening Intent, Colonoscopy, and FIT from T0 to T1 (Mean \pm SE)

CRC screening intent at T0 and T1 for: a: all participants; b: patients with low numeracy; c: patients with high numeracy.
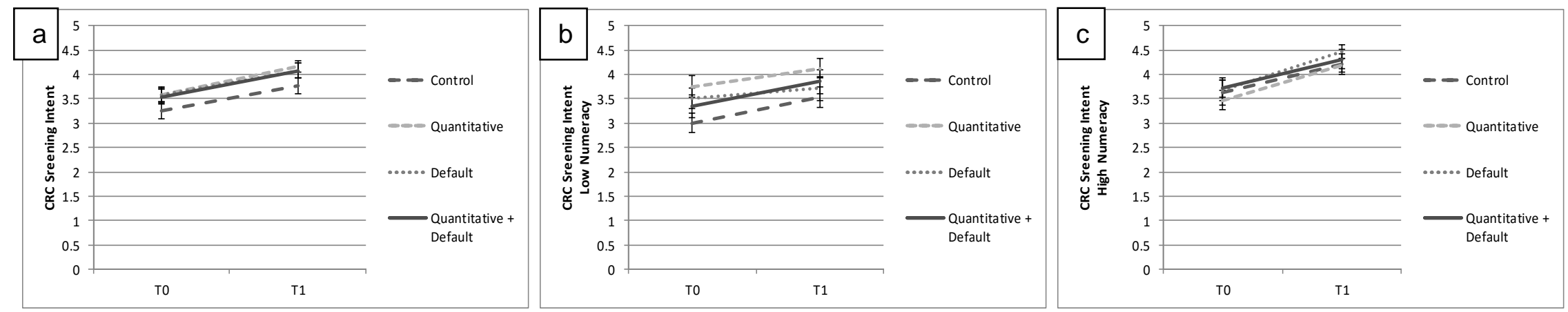

Colonoscopy intent at T0 and T1 for: d: all participants; e: patients with low numeracy; f: patients with high numeracy.
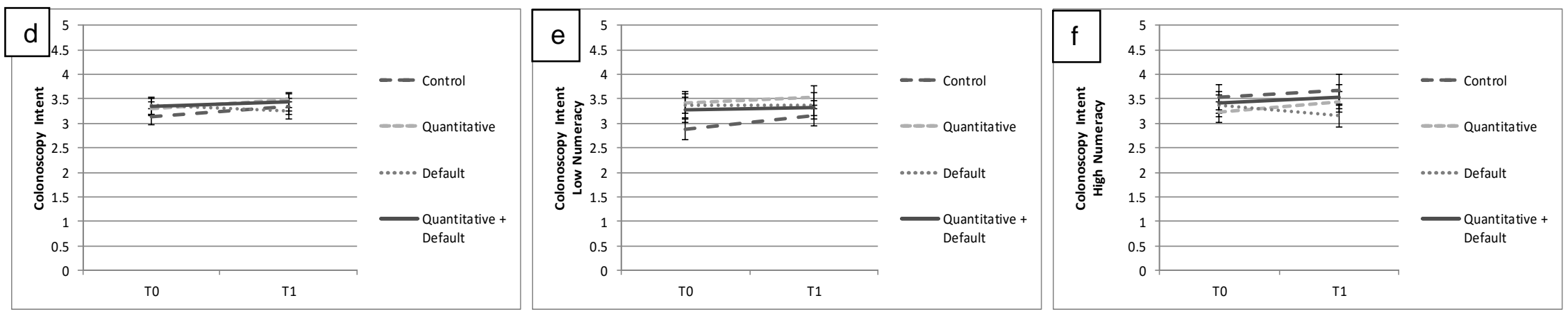

FIT intent at T0 and T1 for: $\mathbf{g}$ : all participants; $\mathbf{h}$ : patients with low numeracy; i: patients with high numeracy.
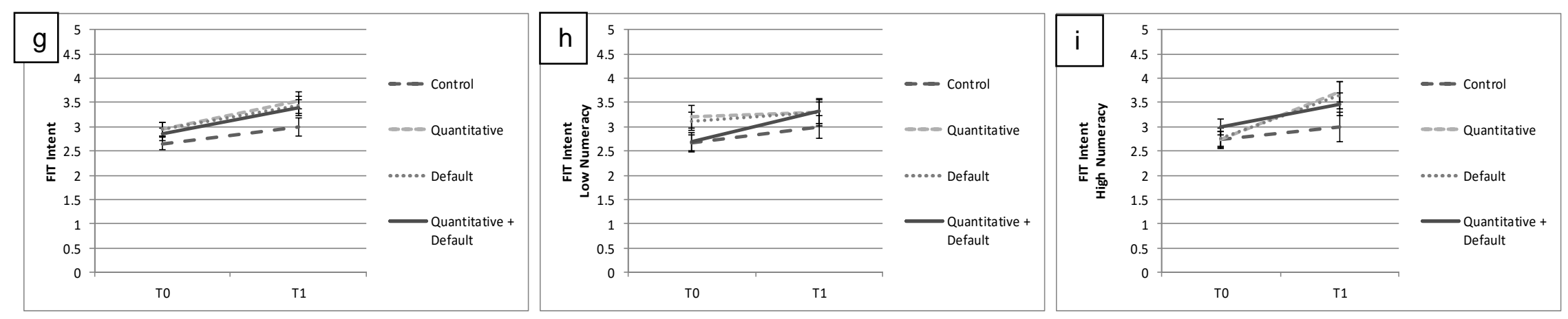